Chapter 13

\title{
Quality by Design and Risk Assessment for Radiopharmaceutical Manufacturing and Clinical Imaging
}

\author{
Kung-Tien Liu, Jian-Hua Zhao, Lee-Chung Men and \\ Chien-Hsin Chen
}

Additional information is available at the end of the chapter

http://dx.doi.org/10.5772/51112

\section{Introduction}

Radiopharmaceuticals have been widely used in many clinical and nonclinical applications, such as in vivo and non-invasive diagnosis or treatment of human diseases. The quality of radiopharmaceuticals administered for a patient is primarily related for the radiation dose delivered to achieve optimizing diagnostic imaging or therapeutic efficacy. Radiopharmaceuticals with different half-lives (short, medium, and long), decay modes (alpha, beta, gamma, and electron capture), and biochemical properties (of ligands) can determine their utilities in medicine. Moreover, chemical and radiochemical impurities in a radiopharmaceutical can produce a serious trouble of diagnosis or treatment. Therefore, different requirements, regulations, and instrumentations for ensuring their high quality and high safety have been developed in many countries.

There are only few years for the progress of "Quality by Design (QbD)" in International Conference on Harmonisation (ICH) Guidelines, e.g. ICH Q8, ICH Q9, and ICH Q10 [1-3]. According to the requirement of ICH Q8, quality can not be tested into products; i.e., quality should be built in by design, i.e. QbD. Enhanced QbD approach to pharmaceutical development can improve the product and process knowledge.

In this chapter, we provide a harmonized framework of $\mathrm{QbD}$ for manufacturing and clinical applications of radiopharmaceuticals in accordance with the requirements and guidelines of U.S. Food and Drug Administration (FDA), International Atomic Energy Agency 
(IAEA), World Health Organization (WHO) and European Association of Nuclear Medicine (EANM). The attributes of the components in the quality system (QA/QC), including organization, staffing and personnel, facilities, instrumentation and equipment, operation procedure, radiopharmaceuticals, protocol and conduct of a study or a treatment, records and reports, and audit framework were further characterized. Assessments and comparisons of critical quality attributes (CQAs) for assuring accurate radioactive dosimetry calculation in the efficiency tracing of absolute activity measurement and patient- and technologistrelated risks for nuclear medicine imaging including Positron Emission Tomography (PET), Computed Tomography (CT), PET/CT, and Single Photon Emission Computed Tomography (SPECT) were identified.

\section{Quality system design based on the Requirements and Guidelines}

\subsection{Quality policy and system}

The quality system by design for radiopharmaceuticals and clinical imaging techniques is aimed to maintain and improve the qualified service for the patients, fulfill the regulatory requirements, optimize the safety and efficacy for patient care, demonstrate a proper equipment operating condition, and obtain a reliable quantitative performance in both diagnostic and therapeutic nuclear medicine procedures [4,5]. The pursuit of excellence in quality system is not a single action over a short period, instead, it is achieved through the whole life cycle of instruments, analytical methods or education for example, from planning and procurement to decommissioning based on advanced technology [6]. Continuous quality improvement implies a commitment to continuously struggle to advance based on state-ofthe-art information and techniques developed by the nuclear medicine and metrology community at large [5].

Implementation of a quality system must be in accordance with the quality police, i.e. the overall quality intentions and direction of an organization, as formally expressed by top management. And quality system includes the structure, responsibilities, and procedures for implementing quality management. An integrated infrastructure of quality policy and system design is demonstrated as in Figure 1, which is mainly developed from the European Standard EN 28402 proposed by Bergmann et al. [7]. The attributes of the components in the quality sub-system (QA/QC), e.g. organization, personnel, facilities, instrumentation, operation procedures, preparation of radiopharmaceuticals, protocol and conduct, records and reports, and audit or inspection, were further integrated and classified in this article. 


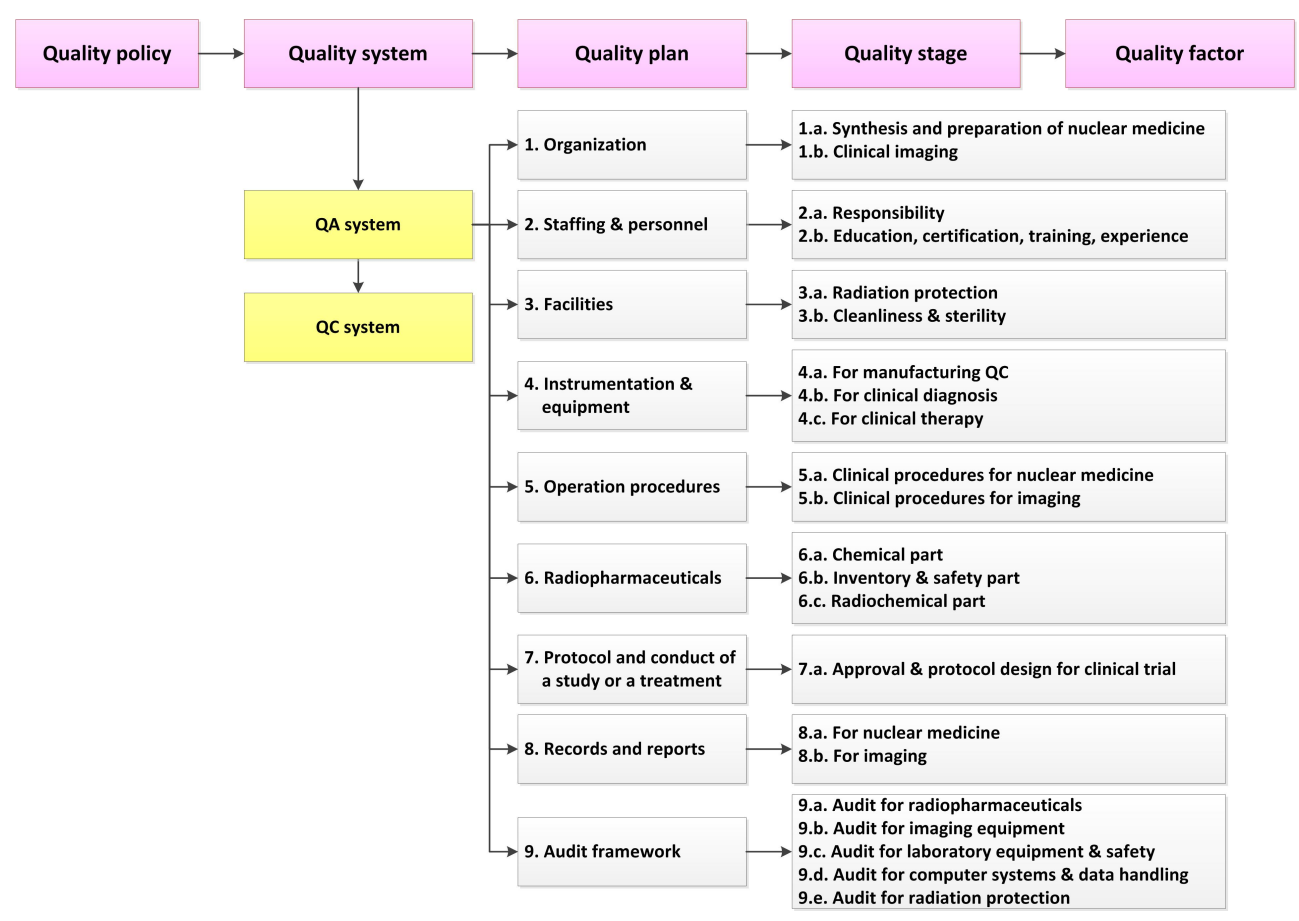

Figure 1. Quality policy and system for the radiopharmaceuticals [7].

\subsection{Quality plan and key factors}

\subsubsection{Organization}

The organization of quality system could be grouped into two categories: (a) synthesis and preparation of nuclear medicine and (b) clinical imaging as shown in Figure 2 [8-10]. For synthesis and preparation of nuclear medicine, three important guidelines were considered [11-13]. Basically, preparation of "classical" radiopharmaceuticals in "kit" procedures and in a "distinct chemical" procedures for PET radiopharmaceuticals are distinguished as two different parts [11].

For the clinical imaging, the major differences PET and SPECT in QbD are related to the properties and applications of a radiotracer. The most commonly used nuclides for PET imaging, such as carbon-11, oxygen-15, nitrogen-13, and fluorine-18, exhibit shorter half-life and more complicated labelling technology than that for SPECT imaging (Table 1)[14-31]. For example, the short half-lives of radionuclides used in PET modality allow for better de- 
tection sensitivity over a given period of time. This is because radiotracers with shorter halflives can be injected in higher activities to the patient without posing any additional radiation damage to the patient (since overall accumulation over time remains the same) leading to the increased detectable radiation over a shorter time. Moreover, arguments that the natural occurrence of PET isotopes in biologically active molecules (as opposed to heavy isotopes used in SPECT) results in a less challenging task of synthesizing physiologically useful tracers in PET modality [32,33]. In general, PET generally has a higher resolution, higher sensitivity, and a better quantitation capability than SPECT. However, SPECT is more practical as a routine procedure [18] and is more cost-effective for the system setting or maintain than a PET facility [8].

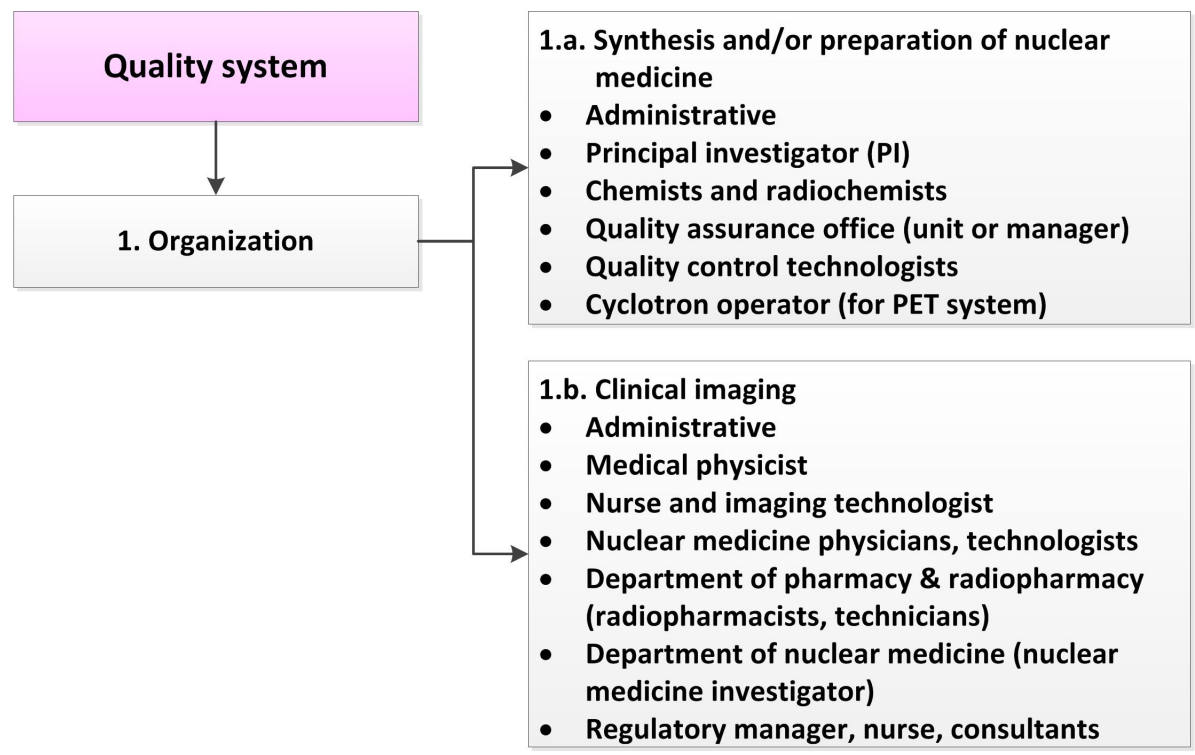

Figure 2. Quality system of organization [8-10].

\begin{tabular}{|c|c|c|c|c|}
\hline Agents & Isotope & $\begin{array}{l}\text { Half-life } \\
\qquad\left(t_{1 / 2}\right)\end{array}$ & Radiopharmaceutical & Applications \\
\hline \multirow{4}{*}{$\begin{array}{l}\text { PET imaging } \\
\text { agents }\end{array}$} & $C-11$ & $20.4 \min$ & C-11-raclopride & D2/D3 dopamine receptor \\
\hline & & & C-11-MADAM & Serotonin transporter \\
\hline & $\mathrm{N}-13$ & $9.96 \mathrm{~min}$ & N-13-ammonia & Blood flow (ventricle) \\
\hline & $0-15$ & $2.07 \mathrm{~min}$ & 0-15 water & $\begin{array}{l}\text { Myocardium perfusion, brain } \\
\text { perfusion }\end{array}$ \\
\hline
\end{tabular}




\begin{tabular}{|c|c|c|c|c|}
\hline & \multirow[t]{3}{*}{ F-18 } & \multicolumn{2}{|c|}{109.8 min F-18-fallypride } & \multirow{2}{*}{$\begin{array}{l}\text { D2/D3 dopamine receptor } \\
\text { Oncology imaging, metabolism of } \\
\text { glucose in tumors, brain and } \\
\text { myocardium }\end{array}$} \\
\hline & & & F-18-FDG & \\
\hline & & & $\mathrm{F}-18-\mathrm{NaF}$ & Osseous metastasis \\
\hline & Cu-64 & $12.7 \mathrm{~h}$ & Cu-64-ATSM & Tumor hypoxia \\
\hline & I-124 & $4.12 d$ & I-124-FIAU & HSV1-tk expresssion \\
\hline & & & I-124-HMFGI (lgG 1$)$ & Breast ductal carcinoma \\
\hline \multirow{13}{*}{\multicolumn{2}{|c|}{$\begin{array}{l}\text { SPECT imaging Tc-99m } \\
\text { agents }\end{array}$}} & $6 \mathrm{hr}$ & Tc-99m-HMPAO & Brain perfusion \\
\hline & & & Tc-99m-ECD & Brain perfusion \\
\hline & & & Tc-99m-TRODAT-1 & Dopamine transporter \\
\hline & & & Tc-99m-Prostascint & Prostate cancer \\
\hline & & & Tc-99m-CEA & Colon cancer \\
\hline & & & Tc-99m-Depreotide & Lung cancer \\
\hline & & & Tc-99m-Annexin-V & $\begin{array}{l}\text { Acute myocardial infarction, } \\
\text { chemotherapy response } \\
\text { monitoring, apoptosis of lung } \\
\text { tumors }\end{array}$ \\
\hline & & & Tc-99m-sestabmbi & Myocardium perfusion \\
\hline & & & Tc-99m-MAG3 & Kidney perfusion \\
\hline & & & Tc-99m-DTPA & Kidney perfusion \\
\hline & & & Tc-99m-DMSA & Kidney perfusion \\
\hline & & & Tc-99m pertechnetate & Thyroid \\
\hline & & & Tc-99m sulfur colloid & Lymph nodes \\
\hline \multirow[t]{9}{*}{$\begin{array}{l}\text { SPECT imagingl } \\
\text { agents }\end{array}$} & $91-123$ & $13 \mathrm{hr}$ & I-123-Iomazenil & $\begin{array}{l}\text { Benzodiazepine ( } \gamma \text {-aminobutyric } \\
\text { acid) receptor }\end{array}$ \\
\hline & & & I-123-IBZM & D2/D3 dopamine receptor \\
\hline & & & I-123-iodobenzofuran & D2/D3 dopamine receptor \\
\hline & & & I-123-epidepride & D2/D3 dopamine receptor \\
\hline & & & I-123-FP- $\beta-C I T$ & Dopamine-transporter \\
\hline & & & I-123-ADAM & Serotonin transporter \\
\hline & & & I-123-IMP & Brain perfusion \\
\hline & & & I-123-Nal & Thyroid \\
\hline & $\ln -111$ & $2.8 \mathrm{~d}$ & In-111-Zevalin & Non-Hodgkin's lymphoma \\
\hline
\end{tabular}




\begin{tabular}{|c|c|c|c|c|}
\hline & & & & \\
\hline & & & In-111-Octreotide & $\begin{array}{l}\text { Somatostatin receptor } \\
\text { (Neuroendocrine tumors) }\end{array}$ \\
\hline & Tl-201 & $3.04 d$ & Tl-201 & Myocardium perfusion \\
\hline & Ga-67 & $3.3 \mathrm{~d}$ & Ga-67 citrate & Non-Hodgkin's lymphoma \\
\hline \multirow{11}{*}{$\begin{array}{l}\text { Therapy } \\
\text { agents }\end{array}$} & Sm-153 & $1.95 d$ & Sm-153 EDTMP & Metastatic bone pain palliation \\
\hline & Sr-89 & $50.5 d$ & $\mathrm{SrCl}_{2}$ & $\begin{array}{l}\text { Palliative treatment of bone } \\
\text { cancers and for prostate cancer }\end{array}$ \\
\hline & P-32 & $14.28 d$ & Orthophosphate & Metastatic bone pain palliation \\
\hline & $\operatorname{Re}-186$ & $3.78 d$ & Re-186-HEDP & Metastatic bone pain palliation \\
\hline & Re-188 & $17 \mathrm{~h}$ & \multicolumn{2}{|c|}{ Re-188-bisphosphonate Metastatic bone pain palliation } \\
\hline & Y-90 & $64.14 \mathrm{~h}$ & \multicolumn{2}{|l|}{ Tiuxetan } \\
\hline & |-131 & $8 d$ & I-131 Tositumomab & B-cell non-Hodgkin's lymphoma \\
\hline & Lu-177 & $6.7 \mathrm{~d}$ & $\begin{array}{l}\text { Lu-177-DOTA-Tyr }{ }^{3} \text { - } \\
\text { Octreotate }\end{array}$ & Small cell lung cancer \\
\hline & Но-166 & $1.1 \mathrm{~d}$ & Ho-166-DOTMP & Multiple myeloma \\
\hline & Sn-117m & $13.6 d$ & Sn-117m-DTPA & Metastatic bone pain palliation \\
\hline & At-211 & $7.2 \mathrm{~h}$ & At-211-81C6 & Glioblastoma multiforme tumors \\
\hline
\end{tabular}

Table 1. Some examples of radiopharmaceutical classification and applications [14-31]. ADAM: 2-((2((dimethylamino)-methyl) phenyl)thio)-5- iodophenylamine; DTPA: diethylenetriaminepentaacetic acid; ECD: ethyl cysteinate dimer; FDG: fluoro-deoxy-glucose; FIAU: 1-(2-fluoro-2-deoxy-B-D-arabinofuranosyl)-5-[I-124]iodouracil; FP$\beta$-CIT: N-propyl-2-beta-carboxy-methoxy-3-beta(4-iodophenyl)-nortropane; HMPAO: hexamethyl propylene amine oxime; IBZM: iodobenzamide.

\subsubsection{Staffing and personnel}

Facilities should have written staff and personnel responsibilities and requirements. Two types of staff in the requirements for synthesis and preparation of nuclear medicine and clinical imaging are necessary [4]:

a. Personnel for synthesis and preparation of nuclear medicine may include such as facility management, administrative staff, study director (SD), principal investigator (PI), production chemists, QA manager or quality assurance unit (QAU), radiochemists, QC chemists, cyclotron operators, and technologists.

b. Personnel for PET and SPECT imaging examination may include such as facility management, administrative staff, medical physicists, nurses, referring physicians, nuclear medicine physicians, radiopharmacist, radiochemists, radiation protection॰ officer, engineers, QA manager or QAU, and technologists. 


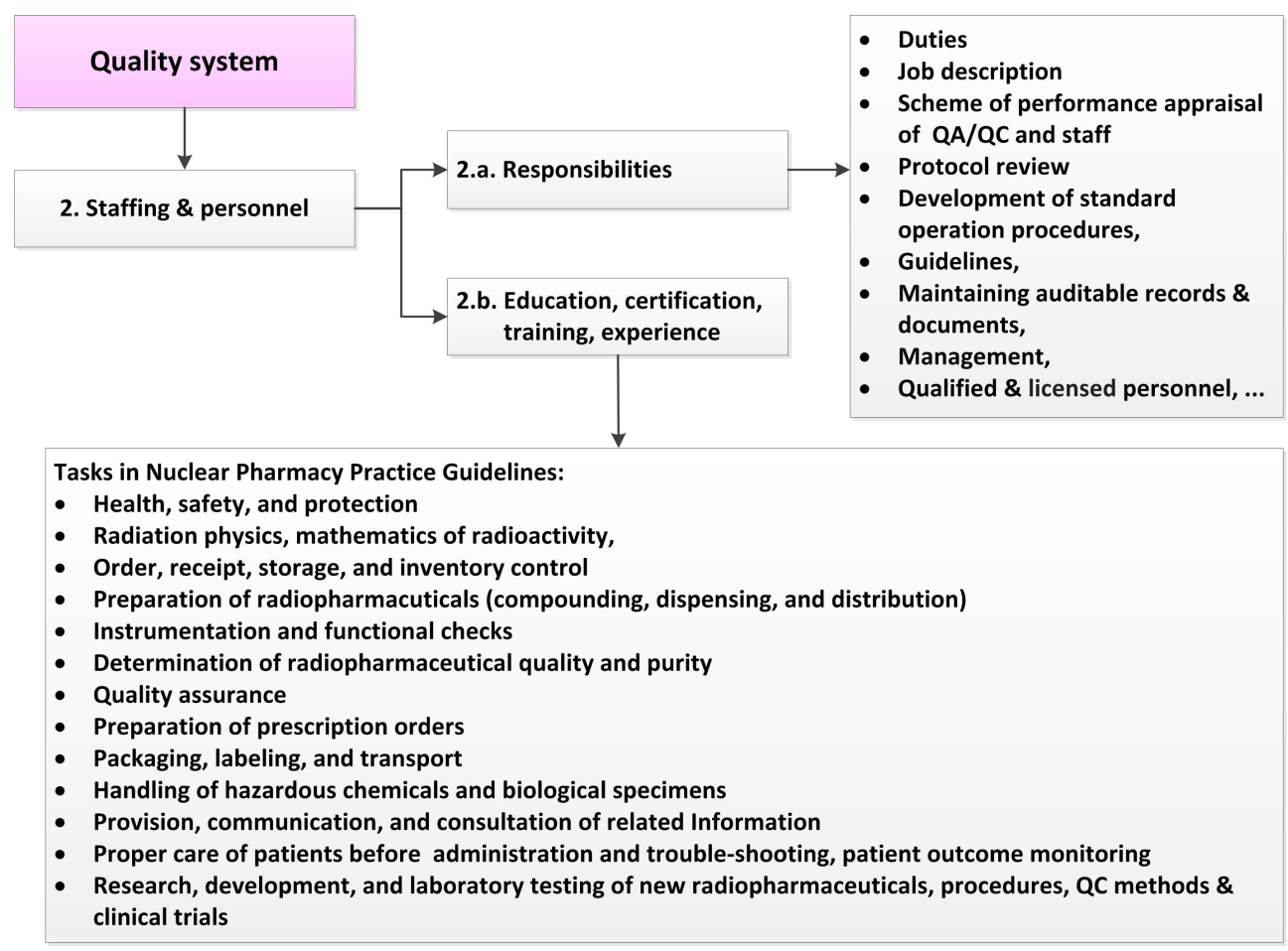

Figure 3. Quality system of staffing and personnel [9,34,35].

The responsibilities for staffing and personnel in a quality system are classified in Figure 3 $[9,34,35]$ and briefly introduced below $[4,6,7,36-38]$ :

a. Facility management: ensure the requirements, guidelines, and practices are complied within facility, sufficient qualified personnel, appropriate facilities, equipment, and materials are available, ensure that personnel clearly understand the functions they are to perform and appropriate and technically valid Standard Operating Procedures (SOPs) are established and followed, ensure that there is a QA manager or QAU with designated personnel and their responsibility is being performed, ensure that for each study an individual with the appropriate qualifications, training, and experience is designated by the management as the SD and PI, ensure that an individual is identified as responsible for the management of the archive.

b. Administrative staff: represent the first encounter a patient has with the centre. They receive the patients according to the established protocols. In collaboration with the medical and technical staff, they are responsible of the application of the procedures for scheduling studies. 
c. SD and PI: they are responsible for approving, conducting, documenting, recording and archiving the overall of the study and for its final report.

d. Nuclear medicine physicians: responsible for quality encompasses the general services of the centre. In particular, supervises all patient care and management procedures and all clinical protocols. In addition, he/she supports and enforces the QA/QC of equipment, establish clinical review and auditing.

e. QA manager or QAU: all those planned and systematic actions necessary to provide adequate confidence that a product or service will satisfy given requirements for quality, express the closeness with which the outcome of a given procedure approaches some ideal, free from all errors and artefacts. Quality assurance embraces all efforts made to this end.

f. Radiopharmacist and Radiochemists (Nuclear pharmacy): they are responsible for compounding, dispensing, quality assessment, patient monitoring, drug use review, new drug development and evaluation, product selection and performance evaluation, pharmacokinetic modeling, drug information and educational services. They are also responsible for the performance of acceptance testing and organization/supervision of routine calibration and QC of all radiopharmacy equipment; QC of chemicals, enriched materials, precursors, and kits; QC of radiopharmaceuticals products and batch release.

g. Cyclotron operators: they are in charge of the daily operations, take part in the acceptance test of the cyclotron and related equipment, and are responsible for calibration and QC procedures for equipment.

h. Production chemists: synthesis and preparation of nuclear medicine.

i. QC chemists: the restriction of QC persons is independent of the production operations or must have independent oversight of these duties. The operational techniques and activities that are used to fulfill requirements for quality and are used in reference to the specific measures taken to ensure that one particular aspect of the procedure is satisfactory.

j. Medical physicists: specialized in nuclear medicine and responsible for the performance of acceptance testing and organization/supervision of routine calibration and QC of imaging and radiation measurement equipment, including radiation protection instrumentation.

k. Radiation protection officer: ensure the radiation safety for patient, staffing, and environmental.

1. Engineers and Technologists: contribute to the preparation of clinical examination protocols and the performance of patient examinations according to the established protocols, involved in the performance of routine calibration and QC of scanners. 
m. Nurses: manage and care of the patient, collaborate in preparing protocols of patient management and information material as well as in checking the operation of other institutional services.

In IAEA, quality manager is responsible for the entire quality management system supervision, the authority to enforce it and act on its findings, and should be involved in the evaluation and periodic review of the results $[5,6]$. But, in EANM, the responsibility for overseeing the preparation operations of a qualified radiopharmaceutical is called QAU [11,12].

\subsubsection{Facility}

In a PET facility, it should include the facility for (a) PET/CT scanner, (b) cyclotron, and (c) radiopharmacy. The location of the facility is a very important issue for the flow of patients, materials, and radiation protection. According to the risk of radiation exposure, two areas are planned [4]:

a. low risk area, cold area or uncontrolled area is the area of offices, reception, waiting room, consulting room, cleaning utilities room or store, and

b. high risk area, hot area or controlled area is the area of hot laboratory, preparation, injection and uptake room, toilet, control and scanning room, post-examination waiting room, reporting room, and waste disposal room.

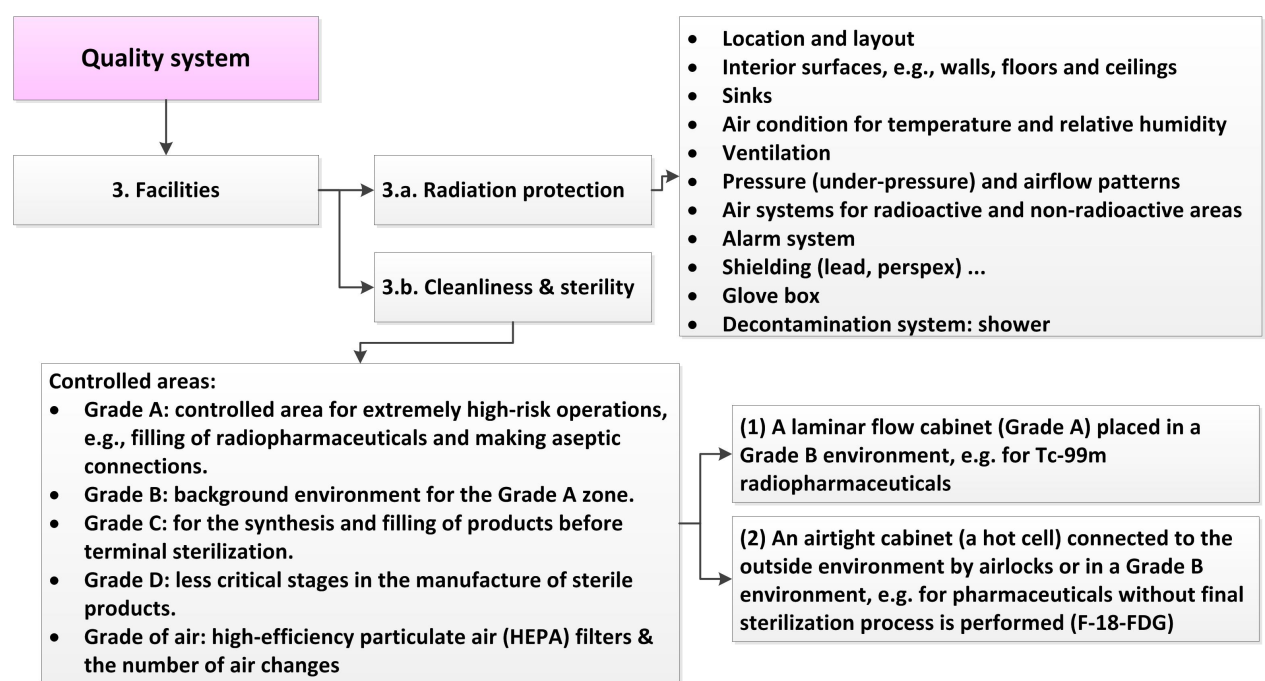

Figure 4. Quality system of facilities [34].

More considerations for the requirements of radiation protection and cleanliness are summarized in Figure 4 [34]. 


\subsubsection{Instrumentation and equipment}

The instrumentation and equipment in the quality system are summarized in Figure 5 $[34,38]$. Apparatus and equipment for the purposes of manufacturing $Q C$, diagnosis, and therapy, including validated computerized systems, used for the generation, storage and retrieval of data, and for controlling environmental factors relevant to the study should be suitably located and of appropriate design and adequate capacity. Apparatus used in a study should be periodically inspected, cleaned, maintained, and calibrated according to SOPs. Records of these activities should be maintained. Calibration should be traceable to national or international standards of measurement [39].

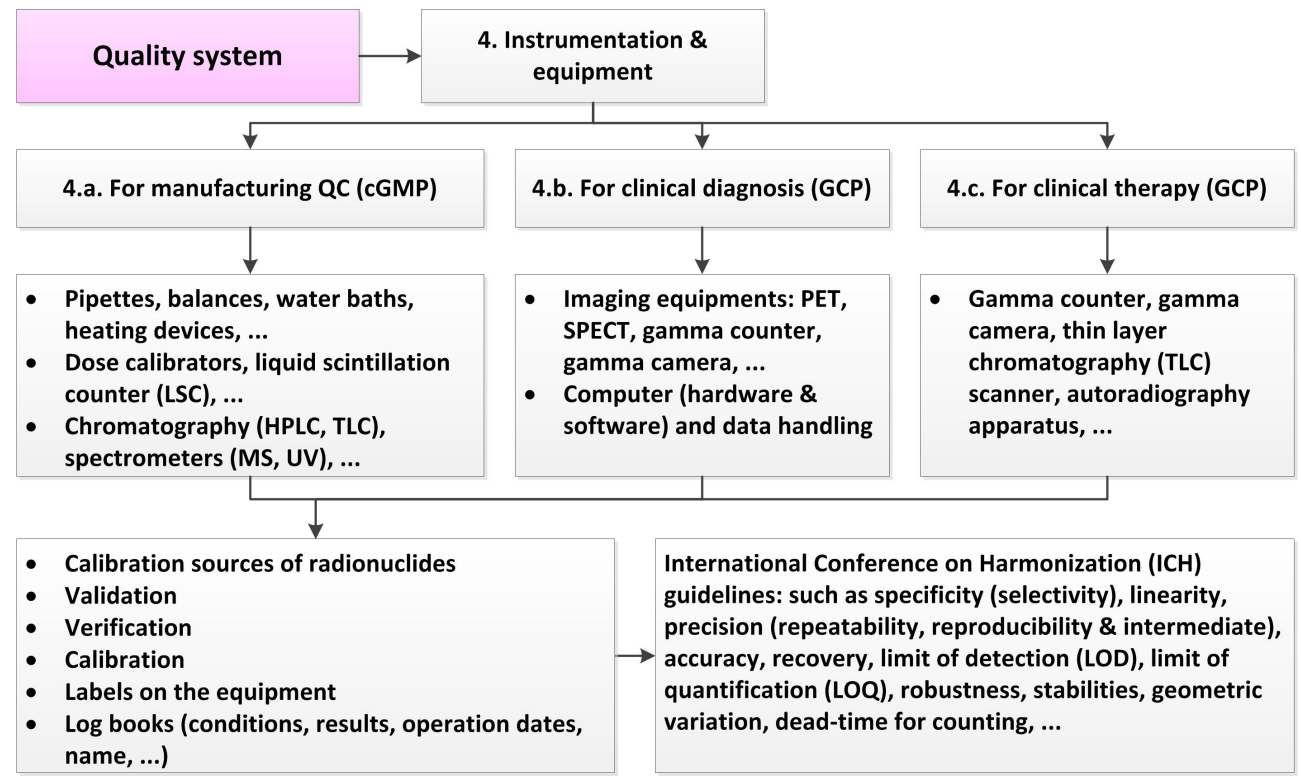

Figure 5. Quality system of instrumentation and equipment [34,38].

Performance tests and operation verification for the nuclear medicine units are achieved daily, weekly, monthly, quarterly, or annually by a qualified medical physicist, a qualified nuclear medicine technologist, or a medical physicist in training, with management by a qualified medical physicist. The tests results of intrinsic or system spatial resolution, uniformity, center of rotation, sensitivity, energy resolution, counting rate parameters, multiple-window spatial registration, formatter and video display, linearity, leak test, overall system performance for imaging systems, interlocks, dose calibrators, thyroid uptake and counting systems must be reviewed and documented in an annual survey report in accordance with the ACR Technical Standard for Medical Nuclear Physics Performance Monitoring of Nuclear Medicine Imaging Equipment [37]. 


\subsubsection{Operation procedures}

A test facility should have written SOPs approved by facility management for ensuring the quality and integrity of the data generation. Deviations from SOPs related to the manufacturing, study, or treatment should be documented and should be acknowledged by the study director, the principal investigator, the medical physician, quality assurance personnel and/or radiopharmacist. The historical file of different version of all SOPs should be well recorded and stored. The requirements of SOPs for nuclear medicine manufacturing and imaging are summarized in Figures 6 and 7 [11,12,40-44].

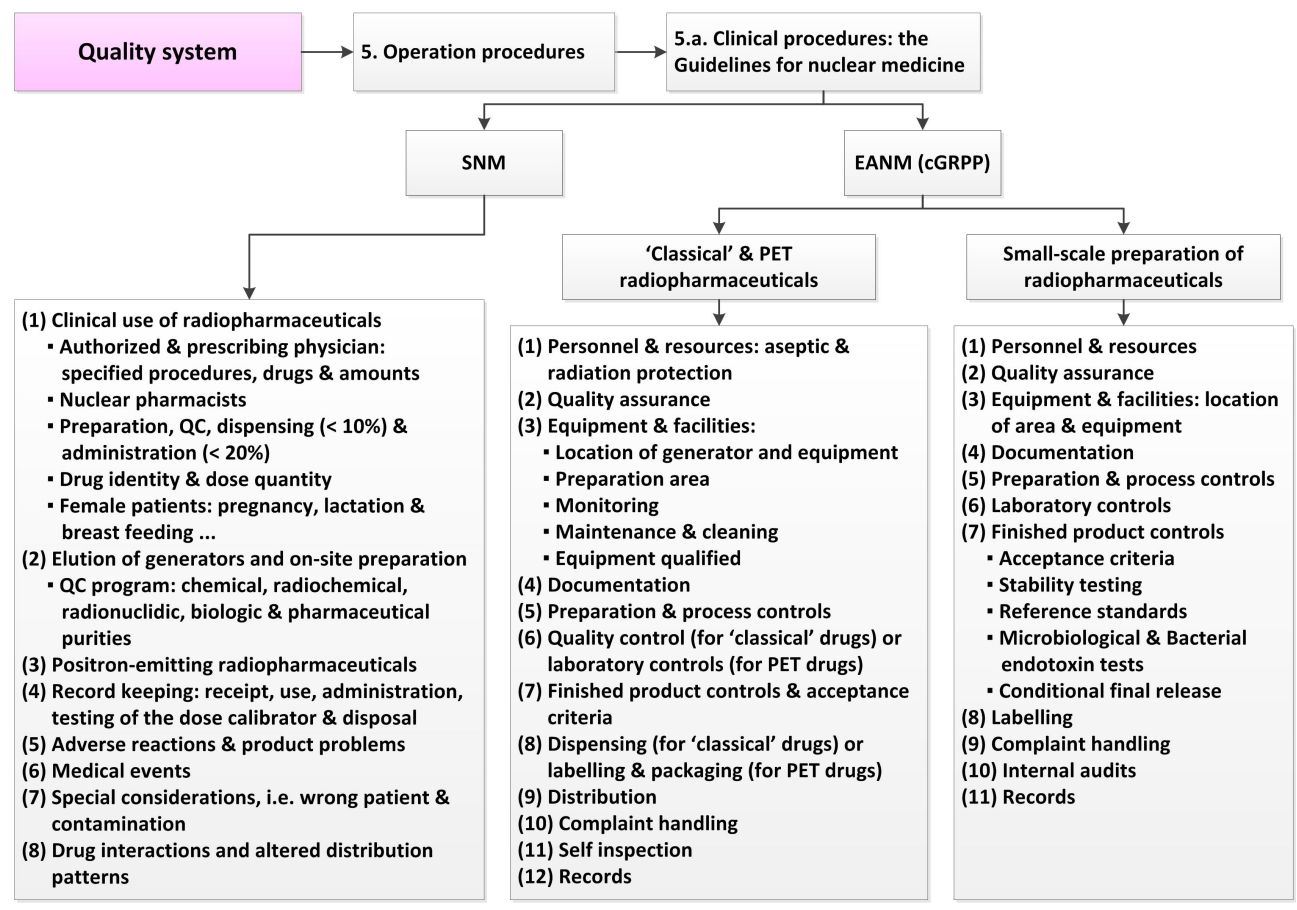

Figure 6. Quality system of clinical operation procedures for nuclear medicine $[11,12,40]$.

\subsubsection{Radiopharmaceuticals}

(a) Manufacturing of radiopharmaceuticals

Manufacturing and quality control plans for radiopharmaceuticals are indicated in Figure 8 [34,40,45]. Radiopharmaceuticals might be manufactured or prepared in hospital radiopharmacies, centralized radiopharmacies, nuclear centers, institutes, industrial manufacturers, or PET centers in accordance with the requirements of good manufacturing practices (GMP) or Current Good Radiopharmacy Practice (cGRPP) [11-13,34]. 
Two categories of radiopharmaceuticals are classified in EANM Radiopharmacy Committee according to the significant difference of preparation procedures, i.e. "kit" and PET radiopharmaceuticals. Also, significant consideration in the "Guidelines on Current Good Radiopharmacy Practice (cGRPP) in the Preparation of Radiopharmaceuticals" is proposed by EANM Radiopharmacy Committee. Two types of preparation methods, i.e. in "classical" procedure and in "synthetical" procedure, have been distinguished in cGRPP [11]. According to WHO guideline, radiopharmaceuticals are divided into four categories including ready-to-use, radionuclide generators, "kits" for the labelled with a radioactive component, and precursors used for radiolabelling other substances before administration (e.g. samples from patients) [13].

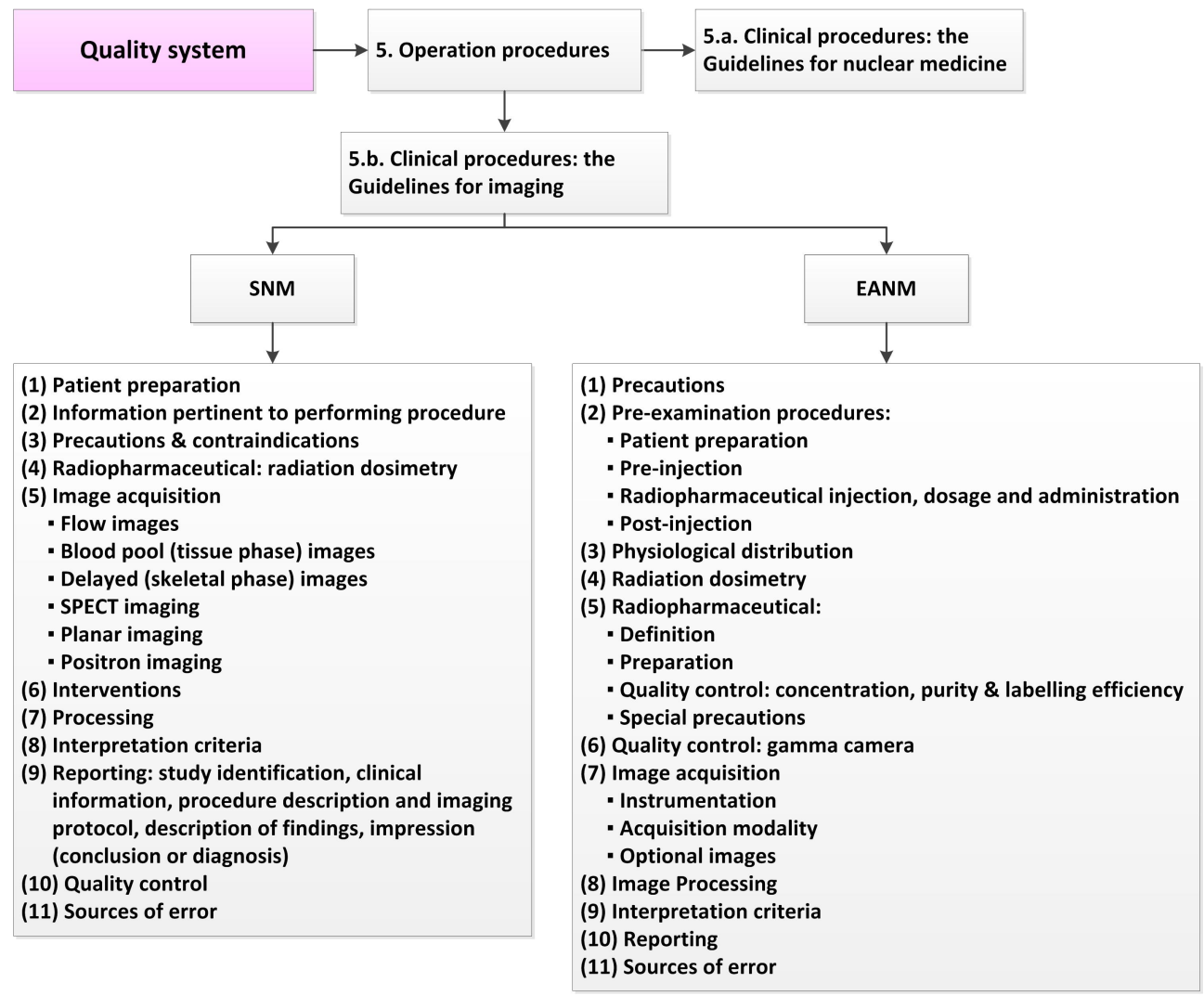

Figure 7. Quality system of clinical operation procedures for imaging [41-44].

Clinical investigations of radiopharmaceuticals can be approved by FDA as "legend drugs." The investigational radiopharmaceutical drug service (IRDS) is responsible for establishing study-specific procedures for radiopharmaceutical drug, including preparation, storage, dis- 
pensing and destruction of investigational drugs within the hospital [9]. Manufacturing or preparation of radiopharmaceuticals must follow the FDA 21CFR Part 212 "Current Good Manufacturing (cGMP) for PET drugs," USP Chapter <797> "Pharmaceutical Compounding-Sterile Preparations," USP Chapter $<823>$ "Radiopharmaceuticals for Positron Emission Tomography - Compounding," and U.S. FDA Guidance: PET Drugs - Current Good Manufacturing Practice (CGMP) [10].

(b) Quality control of radiopharmaceuticals

Three essential parts i.e. chemical, inventory, and radiochemical QC diagrams for radiopharmaceuticals are also indicated in Figure 8 [30,50,45].

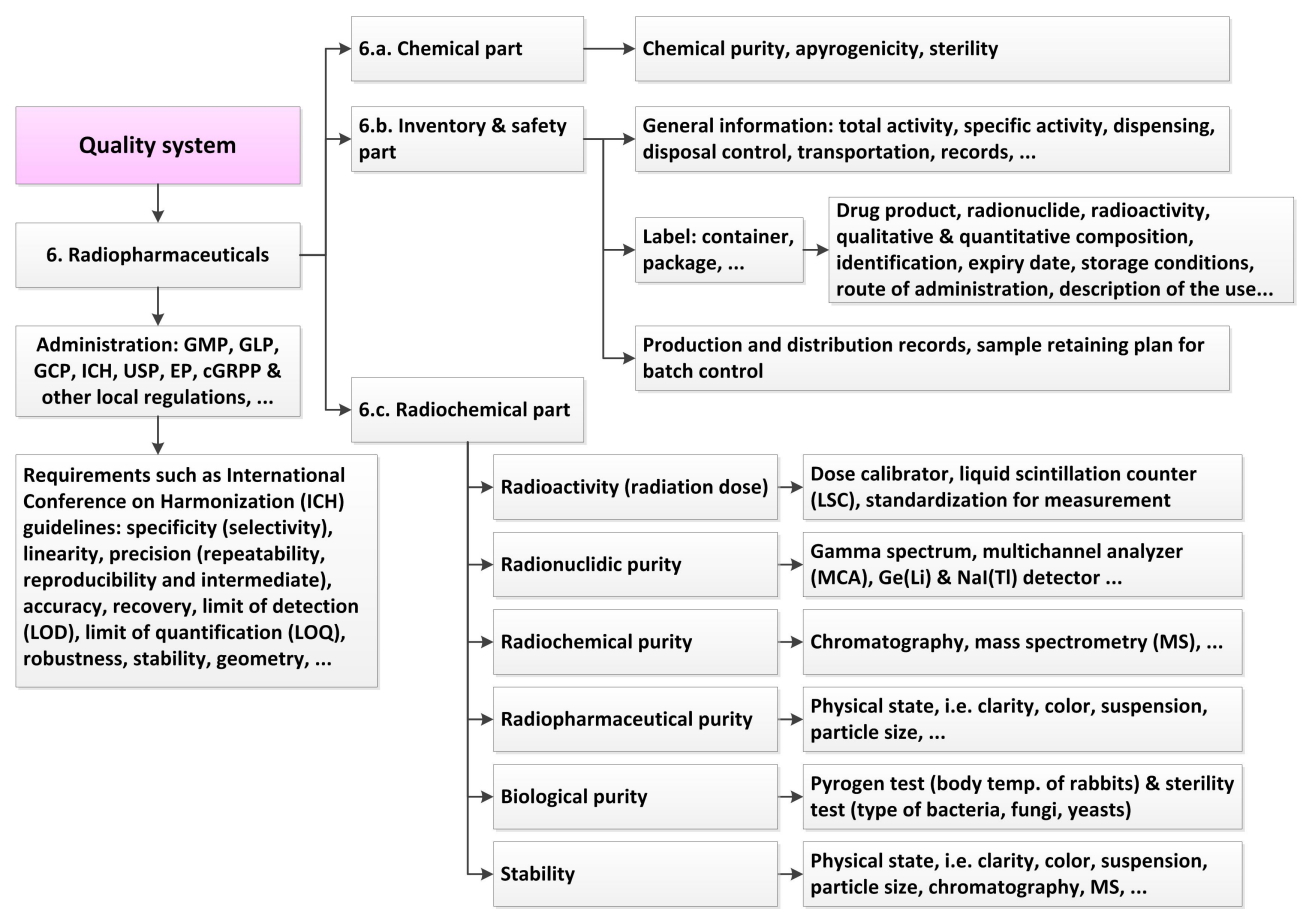

Figure 8. Quality system for radiopharmaceutical manufacturing and quality control $[34,40,45]$.

Method developments for the chemical and radiochemical analysis of starting material, intermediates, precursor used for the radiolabelling, active pharmaceutical ingredient (APIs or drug substance), and finished product (drug product or finished dosage form) are essential requirements of Chemistry, and Manufacturing and Controls (CMC). In the applications of investigational new drug (IND), New Drug Application (NDA), and Abbreviated New Drug Application (ANDA), information on the CMC has to be filed as per 21 CFR 312.23(a) for a drug substance and drug product. The contents for the CMC sections of the 
EU and U.S. are very much the same. However, the sequence and titles of the sections are quite different $[46,47]$.

According to International Conference on Harmonization (ICH) guidelines, the parameters for the validation of analytical methods should basically include specificity (selectivity), linearity, precision (repeatability, reproducibility and intermediate), accuracy, recovery, limit of detection (LOD), limit of quantification (LOQ), robustness, and stability. However, instrument validation parameters for the radioactivity measurement or isotopic analysis, such as dose calibrator or liquid scintillation spectrometry, are partially different.

Radiopharmaceuticals are usually used before all quality control testing has been completed. The implementation of and compliance with the quality assurance program are therefore essential. Principal responsibilities of QA/QC are detailed by WHO and De vos et al., including preparation of detailed instructions for each test and analysis, ensuring the adequate identification, ensuring equipment and process validation, release or rejection of materials, evaluation of the quality and stability of the finished products, expiry dates, storage conditions, control procedures, specifications, and records keeping [13,34].

\subsubsection{Protocol and conduct}

Protocol for a medicine manufacturing study or imaging examination should be evaluated according to the purposes of a study, a treatment, or a clinical trial. Safety issue, such as algorithm proposed by ASNC for maximal benefit in patient radiation exposure must be included [33].

For each study and treatment, a written plan or protocol should exist prior to the initiation of the study. The protocol should be approved by dated signature of the study director, principal investigator or medical physician, facility management, sponsor and verified by quality assurance personnel and/or radiopharmacist. The study and treatment should be conducted in accordance with the study plan or protocol by using a unique identification to each study.

Clinical protocol should be evaluated based on the patient characteristics (e.g. patient history of disease or ability to complete the examination) and complexity of clinical situation in accordance with the current statements and guidelines [33]. For instance, advantages and disadvantages of assessing myocardial perfusion with PET, as compared to SPECT imaging, was reported and concluded that use of very short half-life tracers injected at very high activities, as well as the introduction of increasingly fast scintillators technology, which in turn has allowed reduction of random coincidences and introduced the possibility of timeof-flight (TOF) PET are expected to further contribute to high sensitivity imaging capabilities of PET [32].

An example for approving of protocol design for a clinical trial is shown in Figure. 9 [10,47]. Two pathways for the clinical studies of investigational radiopharmaceuticals are called Ra- 
dioactive Drug Research Committee (RDRC) and IND. For an investigational medical product (IMP, investigation only), if there are adequate data from literature or original assessments that no pharmacologic effects are likely in humans, and the chosen radioactivity is small enough to result in the total radiation absorbed dose, clinical trial can be approved by National Competent Authority (NCA) and Ethical Committee (EC) in EU or approved by RDRC in U.S.. Otherwise, it is approved by EC in EU or approved by FDA in U.S., depending on the phase of drug development [47].

The FDA allows certain unique applications by the local RDRC, consisting of at least five individuals and three individual specialists in nuclear medicine, in formulate radioactive drugs, and in radiation safety, to approve and monitor for the use of radiopharmaceuticals in humans without IND approval. This is due to the low potential for toxicity of radiopharmaceuticals that are typically administered in tracer quantities. Requirements to establish a local RDRC at one's institution is outlined in regulation 21 CFR 361.1. And RDRC has to submit an annual report to the FDA as part of the procedures for maintaining an active and approved RDRC program [48].

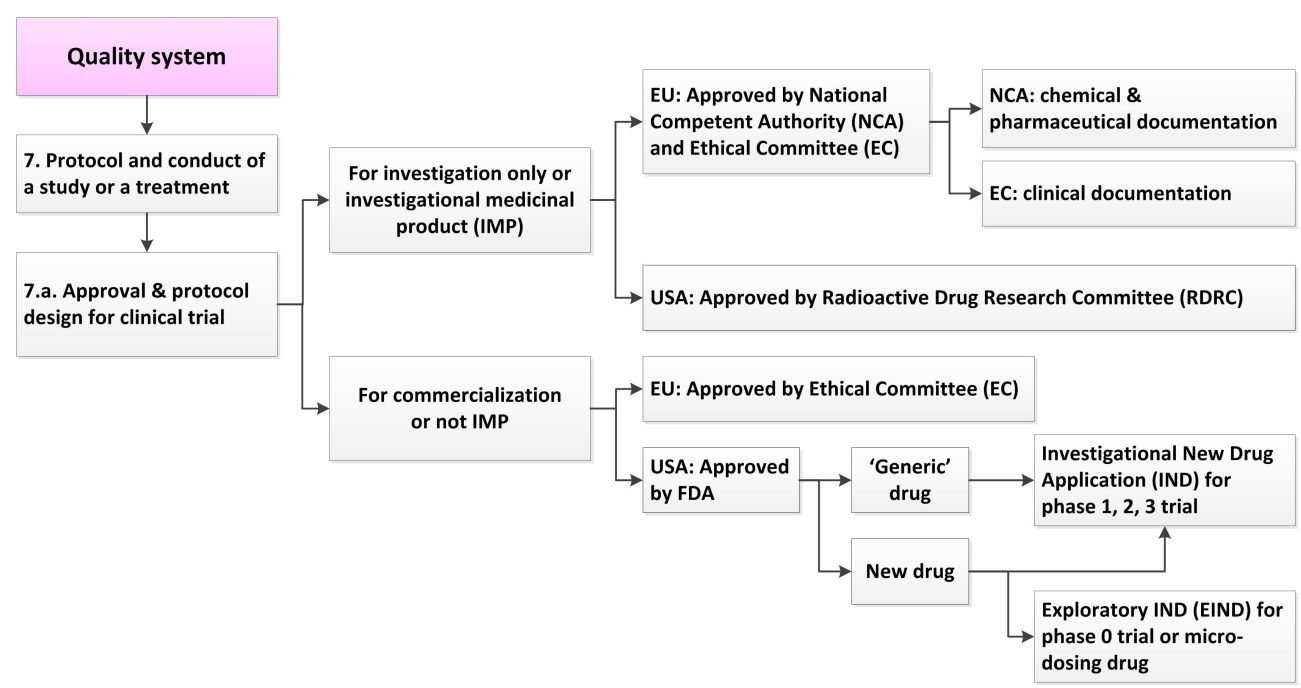

Figure 9. Quality system of protocol and conduct for a study or a treatment $[10,47]$.

\subsubsection{Records and reports}

Records and reports for the manufacturing of radiopharmaceuticals and imaging trial or testing are summarized in Figure 10 [7,9,40-44]. All records and reports should be maintained at the radiopharmaceutical laboratory or another location that is accessible to respon- 
sible officials and to government employees designated to perform inspections [11,12]. Storage of records must ensure safekeeping for many years. Archive facilities of independent locations should be provided for the secure storage and retrieval of study plans, raw data, final reports, samples of test items and specimens. Archive conditions, e.g. fireproof, waterproof, and insect prevention are designed for protecting contents from untimely deterioration [38].

\begin{tabular}{|c|c|}
\hline Quality system & $s$ and reports \\
\hline$\downarrow$ & $\downarrow$ \\
\hline $\begin{array}{l}\text { 8.a. For nuclear medicine: } \\
\text { - Receipt, use, administration, and disposal } \\
\text { of all radiopharmaceuticals } \\
\text { - Receipt of packages, the results of } \\
\text { inspection for physical damage, } \\
\text { measurement of the radiation dose-rate } \\
\text { emanating from the package, and testing } \\
\text { for removable contamination, as required } \\
\text { by the regulatory agency. } \\
\text { - The date and time of preparation, the } \\
\text { quantity, volume, and concentration of } \\
\text { radioactivity used, reagent lot numbers, } \\
\text { QC data, expiration time, waste disposal } \\
\text { information } \\
\text { - Testing of the dose calibrator \& geometric } \\
\text { variation } \\
\text { - Disposal } \\
\text { Archiving }\end{array}$ & $\begin{array}{l}\text { 8.b. For imaging: } \\
\text { - Study identification, } \\
\text { - Clinical information, } \\
\text { - Procedure description and imaging protocol: } \\
\text { radiopharmaceuticals, administration (activity, route), } \\
\text { field of view and patient positioning, processing } \\
\text { protocol ... } \\
\text { - Description of findings: quality of the study, equipment } \\
\text { performance (quality control), data accuracy and } \\
\text { integrity (software quality assurance), data \& image } \\
\text { review, location, extent, and intensity of abnormal } \\
\text { radiopharmaceutical uptake, limitations, accuracy, } \\
\text { timeliness, confidentiality, distribution and comparative } \\
\text { data } \\
\text { - Impression (conclusion or diagnosis) } \\
\text { Training and experience of nuclear medicine specialists \& } \\
\text { operators } \\
\text { Archiving }\end{array}$ \\
\hline
\end{tabular}

Figure 10. Quality system of records and reports [7,9,40-44].

\subsubsection{Audit framework}

Laboratory inspections and study audits should be established for periodical monitoring compliance with GLP, GCP, or GMP principles, study protocol, and SOPs $[9,38]$. Audits for radiopharmaceutical drug products typically begin by confirming the clinical site is appropriately licensed and authorized to receive, possess, store, handle, prepare and administer radiopharmaceuticals. The audit framework of quality system for radiopharmaceuticals, imaging equipment, laboratory equipment, safety, computer systems, data handling, and radiation protection are displayed in Figure 11 [9,39]. 
(a)

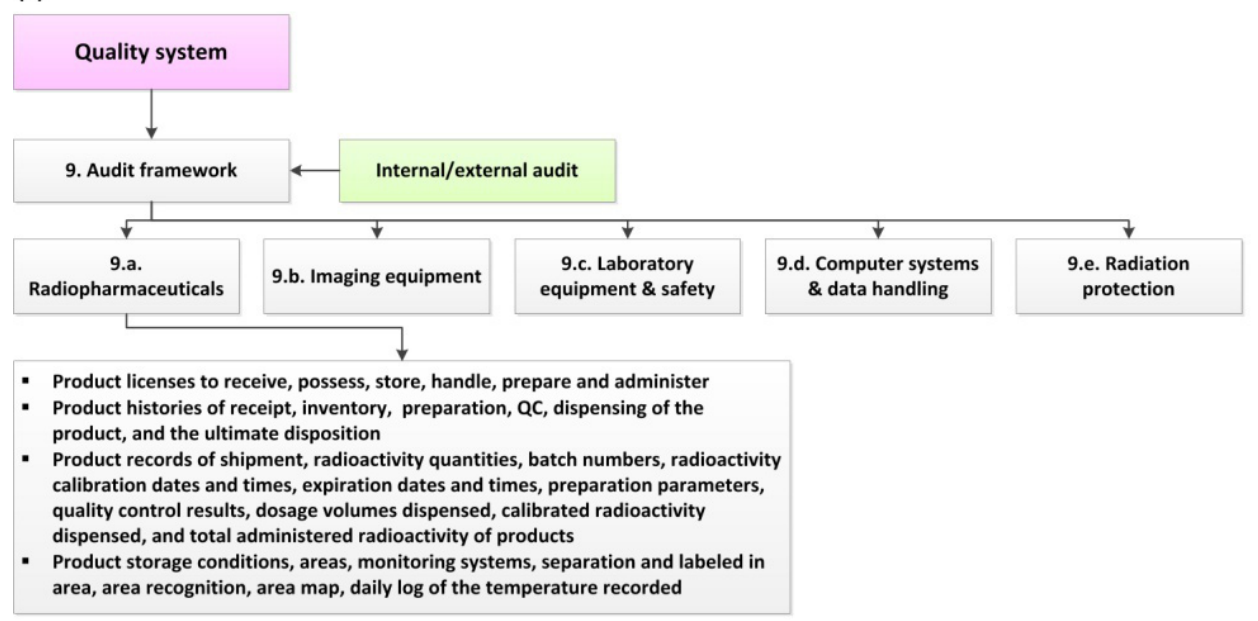

(b)

\begin{tabular}{|c|c|c|c|}
\hline Quality system & $\begin{array}{l}\text { 9. Audit framework } \\
\text { (The BNMS) }\end{array}$ & 9.a. Radiopharmaceuticals & \\
\hline$\sqrt{ }$ & $\downarrow$ & $\downarrow$ & $\nabla$ \\
\hline 9.b. Imaging equipment & $\begin{array}{l}\text { 9.c. Laboratory equipment \& } \\
\text { safety }\end{array}$ & $\begin{array}{l}\text { 9.d. Computer systems \& } \\
\text { data handling }\end{array}$ & 9.e. Radiation protection \\
\hline$\downarrow$ & $\downarrow$ & $\downarrow$ & $\downarrow$ \\
\hline $\begin{array}{l}\text { Documented policies and } \\
\text { protocols for the operation, } \\
\text { QC \& QA for each clinical } \\
\text { gamma camera } \\
\text { - Documented procedures } \\
\text { and results of daily QA } \\
\text { program for the assessment } \\
\text { of gamma camera } \\
\text { functionality } \\
\text { - Documented procedures } \\
\text { and results of QC program } \\
\text { for the measurement of } \\
\text { clinical gamma camera } \\
\text { performance } \\
\text { Documented policies and } \\
\text { testing of new gamma } \\
\text { cameras } \\
\text { - Reference results of gamma } \\
\text { camera } \\
\text { - History logs of gamma } \\
\text { camera }\end{array}$ & $\begin{array}{l}\text { - Documented QA policies } \\
\text { and protocols with records } \\
\text { for equipment } \\
\text { - Departmental safety officer } \\
\text { - Written procedures and } \\
\text { records of radioactive goods } \\
\text { - Written procedures and } \\
\text { records for electrical \& } \\
\text { mechanical safety } \\
\text { - Written procedures and } \\
\text { records for compliance with } \\
\text { hazardous substances } \\
\text { - Written procedures and } \\
\text { training records for manual } \\
\text { handling of goods }\end{array}$ & $\begin{array}{l}\text { - Policy and records for } \\
\text { computer installation } \\
\text { (hardware \& software) } \\
\text { acceptance } \\
\text { - Policy and records for } \\
\text { computer upgrades } \\
\text { - Policy and records for } \\
\text { software QA (commercial \& } \\
\text { in-house) } \\
\text { - Procedure and records for } \\
\text { the assessment of the } \\
\text { integrity of data following } \\
\text { major software revisions } \\
\text { (i.e. count rate losses, data } \\
\text { framing, image } \\
\text { quantification, image } \\
\text { arithmetic, and activity-time } \\
\text { curve arithmetic) }\end{array}$ & $\begin{array}{l}\text { - Warning signs of entrances, } \\
\text { controlled, supervised, } \\
\text { reception, patients' waiting } \\
\text { area \& patients' toilet) } \\
\text { - Local rules for staff and } \\
\text { revised regularly } \\
\text { - Personnel monitored for } \\
\text { radiation exposure } \\
\text { - Syringes shielded } \\
\text { - Decontamination kits } \\
\text { - Contamination monitoring \& } \\
\text { - Monitors calibrated } \\
\text { - Materials stored security } \\
\text { - records, disposal policy, } \\
\text { - Radioactive Substances Act } \\
\text { (RSA) registration and } \\
\text { certificates } \\
\text { - Activity checked prior to } \\
\text { administration \& recorded } \\
\text { - Diagnostic reference level } \\
\text { (DRL) } \\
\text { - Transportation system }\end{array}$ \\
\hline
\end{tabular}

Figure 11. Quality system of audit framework. Audit (a) for radiopharmaceuticals manufacturing, and (b) for imaging equipment, laboratory equipment, safety, computer systems, data handling, and radiation protection. [9,39] 


\section{Quality evaluation and sources of uncertainty}

\subsection{Radiopharmaceuticals}

\subsubsection{Standardization: principle and applications}

Quality control for the quantification of radiopharmaceutical activity is critical for accurate dosimetry calculations, from whole body to cell microscopy. Tumor uptake of radiopharmaceutical need to be correlated with tumor response and to be related to the tumor radiation absorbed dose. [14]

\begin{tabular}{|c|c|c|c|c|c|}
\hline Isotope & $\begin{array}{c}\text { Major decay } \\
\text { modes }\end{array}$ & $\begin{array}{c}\text { Method for } \\
\text { standardization }\end{array}$ & $\begin{array}{c}\text { Detection } \\
\text { efficiency }(\varepsilon)\end{array}$ & $\begin{array}{c}\text { Activity accuracy \& } \\
\text { uncertainty (U) }\end{array}$ & Ref. \\
\hline- & $\begin{array}{l}\beta, \gamma, \beta-\gamma, E C \text {, } \\
E C-\gamma, \alpha, \text { and } \\
\text { mixed decay } \\
\text { nuclides }\end{array}$ & $\begin{array}{l}\text { LSC and C/N } \\
\text { method }\end{array}$ & $\begin{array}{l}\varepsilon_{\text {pure } \gamma}: \sim 100 \% \\
\varepsilon_{\text {pure EC }}:<75 \% \\
\varepsilon_{\mathrm{EC}-\gamma}: \sim 100 \% \\
\varepsilon_{\mathrm{a}}: \sim 100 \%\end{array}$ & $\begin{array}{l}\text { U: } 0.2-0.5 \%(\text { pure } \beta) \\
U: 0.2-0.5 \%(\beta-\gamma)\end{array}$ & 51 \\
\hline Co-57 & $\begin{array}{l}\text { EC decay to } \\
\text { Fe- } 57\end{array}$ & $\begin{array}{l}4 \pi \beta-\gamma \text { coincidence } \\
\text { method }\end{array}$ & $\varepsilon: \sim 75 \%$ & U: $2 \%$ & 50 \\
\hline $\mathrm{Ge}-68 / \mathrm{Ga}$ & & y spectrometer & To ground state: $\beta^{+}$ & $+\mathrm{U}: 1 \%$ & 52 \\
\hline 1. Ge-68 & $\begin{array}{l}\text { EC decay to } \\
\text { Zn-68 } \\
\beta^{+}, E C, y \text { decay } \\
\text { to } Z n-68\end{array}$ & $\begin{array}{l}x \text {-ray spectrometer } \\
4 \pi \beta-\gamma \text { coincidence } \\
\text {-method } \\
\text { LSC } \\
\text { Calibrated IC }\end{array}$ & $\begin{array}{l}(87.85 \%), \mathrm{EC} \\
(8.92 \%) \\
\text { To } 1077 \mathrm{keV}: \beta^{+} \\
(1.29 \%), \mathrm{EC} \\
(1.93 \%) \\
\text { Annihilation } \\
\text { radiation: } 178.29 \% \\
\text { Y-ray to } 1077 \mathrm{keV} \text { : } \\
3.22 \%\end{array}$ & \% & \\
\hline $\begin{array}{l}\text { Sn-117m- } \\
\text { DTPA }\end{array}$ & $\begin{array}{l}\text { - Decay to } \\
\text { Sn-117 }\end{array}$ & $\begin{array}{l}4 \pi \beta L S \text { and } 4 \pi \gamma \\
\text { methods }\end{array}$ & & $\begin{array}{l}U_{C}: 0.60 \% \text { (for DTPA } \\
\text { by LS) } \\
U_{C}: 2.43 \% \text { (for DTPA } \\
\text { by } \mathrm{Nal}(\mathrm{T} 1) \text { ) }\end{array}$ & 17 \\
\hline Cs-131 & $\begin{array}{l}\text { EC decay to } \\
\text { Xe-131 }\end{array}$ & $\begin{array}{l}\text { Coincidence } \\
\text { methods: L Auger } \\
\text { electrons plus L X- } \\
\text { rays and KX-rays }\end{array}$ & - & U: $1 \%$ & 53 \\
\hline Cs-134 & $\begin{array}{l}\beta \text { and } \gamma \text { decay } \\
\text { to } \mathrm{Ba}-134\end{array}$ & LSC & $\varepsilon: \sim 95 \%$ & $\begin{array}{l}3191 \pm 8 \mathrm{kBq} / \mathrm{g} \\
(0.54 \%)\end{array}$ & 54 \\
\hline
\end{tabular}




\begin{tabular}{|c|c|c|}
\hline $\begin{array}{l}4 \pi \beta-\gamma \text { coincidence } \\
\text { method }\end{array}$ & દ: 65-87\% & $\begin{array}{l}3194 \pm 12 \mathrm{kBq} / \mathrm{g} \\
(0.88 \%)\end{array}$ \\
\hline $4 \pi \gamma$ method & $\varepsilon: ~>83 \%$ & $\begin{array}{l}3174 \pm 25 \mathrm{kBq} / \mathrm{g} \\
(2.09 \%)\end{array}$ \\
\hline
\end{tabular}

\section{C/N method}

\begin{tabular}{|c|c|c|c|c|c|}
\hline \multirow[t]{3}{*}{ Tl-201 } & $\gamma$ decays to & High-pressure IC & & & 55 \\
\hline & $\mathrm{Hg}-201$ & $4 \pi \gamma$ coincidence & probability: 0.1000 & $7.197 \pm 0.027$ (NPL) & \\
\hline & & method & \pm 0.0006 & $7.116 \pm 0.050$ (PTB) & \\
\hline \multirow[t]{6}{*}{ TI-204 } & $\beta$ decay & Windowless $4 \pi-$ & & & 56 \\
\hline & $(97.4 \%)$ to & CsI(TI) -sandwich & & & \\
\hline & \multirow{2}{*}{\multicolumn{5}{|c|}{$\begin{array}{l}\text { Pb-204 and EC spectrometer, LSC, } \\
\text { decay }(2.6 \%) \text { PPC }\end{array}$}} \\
\hline & & & & & \\
\hline & \multirow[t]{2}{*}{ to $\mathrm{Hg}-204$} & $\begin{array}{l}4 \pi \beta-\gamma \text { coincidence } \\
\text { method and Cs-134 }\end{array}$ & $\begin{array}{c}\varepsilon_{\beta}: 71-91 \% \\
4 \varepsilon_{\mathrm{EC}}\left(\sim \varepsilon_{\mathrm{AES}}\right): 50-\end{array}$ & $\mathrm{U}_{\mathrm{c}}: 0.76 \%$ & 57 \\
\hline & & tracer & $100 \%$ & & \\
\hline \multirow[t]{7}{*}{$\mathrm{Pb}-210$} & $\beta$ decay to & $4 \pi \beta-\gamma$ coincidence & & $\mathrm{U}_{\mathrm{c}}: 2.7 \%$ & 58 \\
\hline & $\mathrm{Bi}-210\left(\mathrm{t}_{1 / 2}\right.$ & method & & & \\
\hline & $5.103 d)$ & Germanium $\gamma$ & & & \\
\hline & Po-210 $\left(\mathrm{t}_{1 / 2}\right.$ & spectrometry & & & \\
\hline & $138.4 d)$, and & & & & \\
\hline & a decay to & & & & \\
\hline & $\mathrm{Pb}-206$ & & & & \\
\hline
\end{tabular}

Table 2. Some examples of absolute standardization of radiopharmaceuicals and related radioisotopes $[17,50-58]$

The theoretical counting efficiency, i.e. counts/disintegration or counts per minute/disintegration per minute ( $\mathrm{cpm} / \mathrm{dpm}$ ), for a radionuclide can be used to examine the absolute activity, in disintegration or disintegration per minute $(\mathrm{dpm})$ of the radionuclide. Different efficiency tracing methods has been developed for more than six decade by characterizing the effects of sample volume, medium composition (matrix), pulse discrimination conditions, photomultiplier voltage, amplifier gain, and luminophor concentration on counting efficiency of a radioactive species [49]. The use of $4 \pi \beta$ scintillation counting and $4 \pi \beta-\gamma$ coincidence counting for the standardization of certain electron capture (EC) nuclides with simple decay schemes is established since 1952 [49] and 1957 [50].

Some examples of absolute standardization of radiopharmaceuicals and related radioisotopes are shown in Table 2 [17,50-58]. Below, we introduce different tracing methods, including (a) efficiency tracing (and extrapolation) method using a non- $\mathrm{H}-3$ standard solution, (b) CIEMAT-NIST (C/N) efficiency tracing method, (c) non-extrapolation tracer method, (d) coincidence method by a $4 \pi \beta-\gamma$ system, (e) triple to double coincidence ratio (TDCR) method, and (f) $4 \pi \gamma$ counting method.

(a) The efficiency tracing (and extrapolation) method using a non- $\mathrm{H}-3$ standard solution 
The efficiency tracer techniques, using Co-60, Cs-134, C-14, Cr-51, Mn-54 or Am-241 standard solution for the standardization of the $\beta-\gamma$ nucides were developed. The $4 \pi$ liquid scintillation (LS) consisted of the extrapolation of the $4 \pi$ counting rate to the zero discrimination level for the standardization of the Tl-204 (97.6\% $\beta$ emission and 2.4\% electron capture) solution was carried out for efficiency tracing using a Co-60 standard solution received in the framework of the 1997 BIPM comparison was carried out by Sahagia et al. [59]. A germanium spectrometer was calibrated for the standardization of Pb-210 using Am-241 as a normalizing agent has been proposed [58]. Instead, Dias et al. chose Cs-134 as an efficiency tracer to standardize Tl-204 as well as a $4 \pi \beta-\gamma$ coincidence system for the calibration [57]. This method can be also successfully used for the standardization of radionuclides such as Ir-192, Zn-65, Mn-54, with the detection of the $\beta$ rays, Auger electrons, $X$ rays, in the proportional counter (PC) [60]. Efficiency tracing with C-14 and zero detection threshold techniques with $\mathrm{H}-3$ as tracers was applied for standardization of various $\beta$-emitting radionuclides, e.g. C-14, Cl-36, and Tl-204 using LS spectrometer [61].

Recently, different methodologies were proposed. Koskinas et al. developed a "dual-tracers", e.g. Cr-51 and Mn-54 procedure followed by the Laboratório de Metrologia Nuclear (LMN) for the standardization of EC nuclide, i.e. Fe-55. The efficiency was obtained by selecting a $\gamma$-ray window set at $320 \mathrm{keV}(\mathrm{Cr}-51)$ and at $834 \mathrm{keV}(\mathrm{Mn}-54)$ [62]. The activity of EC radionuclides is usually determined by $4 \pi$ (proportional counter, PC) $-\gamma$ coincidence counting and by an efficiency extrapolation method. However, an alternative method, called "wet extrapolation method", utilizes an absorption change during the drying of a water droplet added onto the source surface, variation of the PC detection efficiency can be achieved. Slopes of extrapolation curves and resulting activity values obtained are compared for several radionuclides (Mn-54, Ce-139, Y-88, and Co-57) [63].

(b) The CIEMAT-NIST (C/N) efficiency tracing method

CIEMAT/NIST (C/N) method, developed by Centro de Investigationes Energéticas, Medioambientales y Tecnologicas (CIEMAT), Spain and the National Institute of Standards and Technology (NIST), U.S. is used for standardization of radionuclides with Liquid Scintillation (LS) Spectrometry by calculating the counting efficiency of the radionuclide to be assayed and using $\mathrm{H}-3$ as a tracer [61]. C/N program is suitable used for the calculation of the efficiency of nuclides decayed by $\beta, \beta-\gamma, \mathrm{EC}, \mathrm{EC}-\gamma$ and nuclides with mixed decay [51]. The basic principle of $\mathrm{C} / \mathrm{N}$ LS efficiency tracing method is a combination of a theoretical calculation of the counting efficiency and an experimental determination of correction factors in three steps [61,64]:

- Count rates (cpm) and the quench-indicating parameters (QIPs, i.e. tSIE) are determined for a set of samples of the nuclide to be measured, and for a set of H-3 standard samples, with a different quench. The tSIE values were calculated using the Ba-133 source inside of the instrument. By combining these data, a corresponding H-3 efficiency is obtained for each sample of the nuclide.

- The universal curve of Figure of Merit (FOM) as a function of tSIE was plotted. The efficiency of the nuclide is theoretically calculated as a function of the efficiency of the tracer nuclide $\mathrm{H}-3$. 
- This relation is used in conjunction with the measured data to calculate the efficiency for the nuclide and an activity value in dpm for each single measurement.

The parameters of emitters in different decay modes used for the $\mathrm{C} / \mathrm{N}$ calculations are summarized as follows [51]:

- Pure $\beta$ emitters (Sr-89, Sr-90, Y-90, and K-40): atomic number Z of the radionuclide, the mass number A, the endpoint energy EMax, and the shape parameters.

- Pure $\gamma$ emitters (Nb-93m): the efficiency is nearly $100 \%$.

- $\beta+\gamma$ emitters, if the radionuclide has significant levels with half-lives in the order of the coincidence resolving time or the dead time of the equipment, a $\mathrm{C} / \mathrm{N}$ calculation is not possible.

- Pure EC emitters: the input parameters are the capture probabilities, PK; PL; PM, and the atomic parameters for the rearrangement: the fluorescence yields $\omega \mathrm{K}$ and $\omega \mathrm{L}$ (averaged), the probabilities of the X-rays (PKL, PKX, and PLX) and their average energies (EKL, EKX, and ELX), the emission probabilities of the Auger electrons (PKLL, PKLX, PKXY, and PLXY) and their average energies (EKLL, EKLX, EKXY, and ELXY).

- EC+ $\gamma$ emitters (Co-57, Se-75, Sr-85, and Ba-133): the calculation method is the same as for $\beta+\gamma$ nuclides.

- The efficiency of LSC systems with respect to alpha radiation is in each case very close to unity. A tracer method is not necessary.

(c) The non-extrapolation tracer method

An alternative called "non-extrapolation tracer method" was proposed by Steyn et al. in 1979, where Fe-55 was used as a tracer to establish the figure-of-merit (FOM) of the detection system for the calculation of counting efficiency [65]. The liquid scintillation method, for the determination of absolute activity of Mn-54 and Zn-65 from $4 \pi(\mathrm{LS}) \mathrm{e}-\gamma$ data by direct calculation without efficiency extrapolation was performed. The non-extrapolation LS method relies on determining the probability of the $\gamma$-ray interacting with the scintillator solution, is described and validated by measurements made on Co-60 [66].

(d) The coincidence method by a $4 \pi \beta-\gamma$ system

Coincidence method comes from the additional coincidence channel, which records a disintegration event when it is detected in both $\beta$ - and $\gamma$-channels. Typically, the system for absolute standardization is usually consisted of a gas-flow or pressurized proportional counter with $4 \pi$ geometry as the $\alpha, \beta$, electrons or X-ray detector and coupled to a pair of $\mathrm{NaI}(\mathrm{Tl})$ scintillation counters or a semiconductor detector, as $\gamma$ detectors. The $4 \pi \beta-\gamma$ coincidence technique has been considered a primary standardization method due to its high accuracy and because it can obtain the radionuclide activity depending only on observables quantities $[57,67]$.

Alternatively, solid or liquid scintillation counters (LSC) are used in place of gas-flow proportional counters. Advantages of using LSC counting in the $4 \pi$ channel are that self-absorption does not occur, leading to Auger electrons being detected with relatively high 
efficiency; source preparation is easy; and the source geometry is highly reproducible. The latter leads to good reproducibility of the counting efficiency of the X-rays and Auger electrons, which in turn gives rise to consistent results amongst the counting sources. The efficiency data can generally be fitted with a linear function, particularly in the high-efficiency region, or by a low-order polynomial expression, giving rise to reliable extrapolated activity values [68].

Several examples for the applications of the coincidence method by a $4 \pi \beta-\gamma$ system are such as standardization of Ho-166m using the normal gas flow $4 \pi \beta-\gamma$ coincidence method [69], standardization of Tl-204 using Cs-134 as tracer and a $4 \pi \beta-\gamma$ coincidence system was used for the calibration [57], directly measured of radionuclides with EC decay schemes, e.g. I-125, Ir-192, Zn-65, and Ce-139 by a LS coincidence extrapolation technique [68], and standardization of Fe-55 using a "dual-tracers" method coupled with a $4 \pi \beta-\gamma$ coincidence calibration system [62].

(e) The triple to double coincidence ratio (TDCR) method

The TDCR method was first developed at the R.C., Poland and at the LNHB, France. The equipment consists in a detection unit, provided with three photomultipliers (PMs), acted by the light emitted in the vial containing the radioactive solution dissolved in a liquid scintillator, and the electronic unit [60]. TDCR, allowing the observation of three kind of double coincidences (2-photodetectors) and triple coincidence (3-photodetectors) method in LSC, is a fundamental measurement method suitable to the standardization of pure-beta emitters, i.e. H-3, C-14, P-32, Ni-63, Tc-99, Tl-204 and some low energy electron-capture emitters, i.e. Fe-55 [59,60,70,71]. Detection efficiency variation can be achieved using techniques of chemical quenching, coaxial grey filters and PM tubes defocusing. The two former processes reduce the mean quantity of light emitted and the later reduces the detection probability [71]. Basically, the specific experimental parameter $(\mathrm{K})$ is equal to the ratio of the triple coincidences counting rate $\left(\mathrm{N}_{\mathrm{T}}\right)$ to the sum of double coincidences counting rate $\left(\mathrm{N}_{\mathrm{D}}\right)$. Determination of a counting efficiency $\left(\varepsilon_{\mathrm{D}}\right)$ for each counting point $\left(\mathrm{N}_{\mathrm{D}}\right)$ leads to the activity of the source $\left(\mathrm{N}_{0}\right)$. The efficiency functions $\varepsilon_{\mathrm{T}}$ and $\varepsilon_{\mathrm{D}}$ are nonlinear functions for a particular emitter and counting system [70].

Two innovative TDCR instrumentations were developed:

- The TDCR method of LSC is well established for measuring the activity of pure beta emitting and electron capture radionuclides. Recently, a new TDCR counting system was designed by the National Physical Laboratory (NPL) for activity assays of low-energy, pure $\beta$-emitting radionuclides and EC nuclides. Three photomultiplier tubes (PMT) were arranged in the optical chamber as well as a $\mathrm{NaI}(\mathrm{Tl})$ detector was mounted below the optical chamber. The detector allows $4 \pi \beta-\gamma$ coincidence measurements to be performed in parallel [72].

- Radionuclides such as P-32, Sr-89, Y-90, T1-204, and Rh-106 were successfully studied using an in-house built new TDCR-Čerenkov counter developed by Kossert. Since Čerenkov counting acts as natural discrimination for $\alpha$ emitters and low-energy $\beta$ emitters, some potential radioactive impurities or progenies will not disturb the measurements. Two standard sources, e.g. $\mathrm{Cl}-36$ and P-32 were used to determine the free parameter and to 
calculate the Čerenkov counting efficiencies. Since Čerenkov counting is more sensitive to changes in the computed $\beta$ spectra, the method was extensively used to investigate $\beta$ shape factor functions [73].

(f) The $4 \pi \gamma$ counting method.

An ionization chamber system referring to a long living and stable standard source is very adequate for the comparison of $\gamma$-ray emitting radio-nuclides. In most cases Ra-226 sealed sources have been used as the reference because the Ra-226 sources were widely used in radiotherapy [69]. Zimmerman et al. standardized and compared solution of Sn-117m by $4 \pi \beta$ liquid scintillation (LS) spectrometry and $4 \pi \gamma$-ray spectrometry ( $\mathrm{NaI}(\mathrm{Tl})$ and high-purity germanium detectors). Massic activities were measured for determining the dose calibrator factor settings [17].

\subsubsection{Uncertainty of measurement}

Examples for the evaluation of detection efficiency $(\varepsilon)$, activity accuracy, and measurement uncertainty $(\mathrm{U})$ of absolute activity of radiopharmaceuicals and related radioisotopes are shown in Table 2. Components of combined uncertainty were further summarized in this section.

(a) Uncertainty for the efficiency tracing (and extrapolation) method using a non-H-3 standard solution

Components of combined uncertainty in the activity determination include counting statistics, background, dead time, weighing, decay scheme parameter, half-life, and extrapolation of efficiency curve [57]. Source of uncertainty evaluated by Woods et al. in the absolute standardization of low energy $\beta$ emitter, i.e. $\mathrm{Pb}-210$ are counting, background, half life, $\beta$ dead time, $\gamma$ dead time, resolving times, choice of fit, count rate dependence, dead time formula, weighing, separation time, extrapolation range, contaminants, and reproducibility [58].

(b) Uncertainty for the $\mathrm{C} / \mathrm{N}$ efficiency tracing method

Component of uncertainty in the standardization of Re-186 by the C/N method of LS efficiency tracing with $\mathrm{H}-3$ include source preparation, scintillator stability, dead time, liquidscintillation measurements, uncertainty due to $\mathrm{H}-3$ reference standard, EC/ $\beta$ - branching ratio, spectral distributions for EC and $\beta$ - branches. [74]

The contributions to the uncertainty of the value of the specific activity are volatility of $\mathrm{H} 2$ [GeCl6] during the preparation of solid sources for coincidence measurements, drop masses, counting statistics, background variation, accidental coincidences and dead time losses, Compton continuum of the $1077 \mathrm{keV}$ peak included in the $\gamma$ window around the $511 \mathrm{keV}$ peak, decay scheme correct ion factor, correction factor for non-vanishing $\varepsilon E C$, impurities and halflife uncertainty, and detection of $511 \mathrm{keV}$ quanta in the $\beta$ detector due to its $\gamma$ sensitivity [52].

The components contributing to the uncertainty of $4 \pi \beta-\gamma$ coincidence method were estimated as follows: counting statistics and background variation, instrumental corrections, impurities, half-life uncertainty, decay scheme correction factor, and mass of droplet. Standard 
deviation of LSC composed of the following contributions: counting statistics, background variation, scintillator stability, comparison with H-3 tracer, instrumental corrections (dead time), dilution factor, droplet mass, radioactive impurities, half-life uncertainty, main decay data, uncertainty of the $\varepsilon$ calculation due to the K-L model, capture probabilities $\mathrm{P}_{\mathrm{K}^{\prime}}, \mathrm{P}_{\mathrm{L}}$, fluorescence yields, $\omega_{\mathrm{K}}, \omega_{\mathrm{L}}$, spectral distribution of $\beta$ particles, and average energy of weak Auger electrons [75].

Source of the uncertainty: counting statistics, mass, dead time, background, timing, chemical effects (adsorption, sample spread, impurities), input parameters and statistical model, quenching, kB influence, decay scheme parameters, and pulse shape discriminator setting. [76]

(c) Uncertainty for the non-extrapolation tracer method

The quoted total uncertainty $(1 \sigma)$ of $0.85 \%$ comprised mainly the components due to counting statistics $(0.28 \%)$, afterpulsing $(0.40 \%)$ and the evaluated decay-scheme data $(0.63 \%)$. $\varepsilon_{\mathrm{M}}$ : double tube detection efficiency of Mn-54, $\varepsilon_{\mathrm{M}}{ }^{*}$ : reduced Mn-54 efficiency due to quenching caused by the addition of the Fe-55 aliquot [65].

(d) Uncertainty for the coincidence method by a $4 \pi \beta-\gamma$ system

Uncertainty components assayed by Koskinas et al. for the standardization of Eu-152 were counting statistics, weighing, dead time, impurities, half life, extrapolation of efficiency curve [77].

(e) Uncertainty for the TDCR method

The main source of uncertainty of TDCR method comes from the model describing the nonlinearity of the scintillator due to the ionization quenching phenomenon [71]. Type A standard uncertainty, i.e. counting statistics and type B standard uncertainty, i.e. extrapolation (interception uncertainty), spurious pulses, nonuniformity of sources, tracer activity, E. C. correction, dead-time, background, half-life, weighing were evaluated by Sahagia et al. [59].

(f) Uncertainty for the $4 \pi \gamma$ counting method.

Construction of an ionization chamber efficiency curve is not a straightforward process as the curve has to be extracted from experimental calibration points analytically. The efficiency curve is implicitly contained in individual radionuclide coefficients and these are obtained experimentally or by Monte Carlo modelling or calculated back from the efficiency curve. Due to this variety, the interpretation and intercomparison of different efficiency curves is often hard and transferring individual radionuclide calibration coefficients between ionization chambers of different constructions is not a simple process [78].

\subsubsection{International measurement program}

One of the most important components in the quality system of radiopharmaceuticals is to establish the measurement traceability to international standards for ensuring the accurate and consistent of measurement results [5]. Traceability of activity measurements is the critical part in the production and use of unsealed radioactive sources in nuclear medicine. The U.S. Nuclear Regulatory Commission (NRC) defines a medical event as a patient receiving 
an injected activity greater than $20 \%$ different from the prescribed dosage. Tthe Society of Nuclear Medicine (SNM) guidelines also recommend that the measurement be with $10 \%$ of the prescribed dosage. Moreover, the instruments being used are capable of accurate measurements to within 5\% [79]. Therefore, programs for the establishment and dissemination of activity measurement standards in nuclear medicine are held in many countries.

International comparison of standard sources and solutions, such as P-32, Mn-54, Zn-65, Ir-192, Tl-204, and Am-241, which is organized by the International Committee of Weights and Measures (CIPM), the EUROMET system, the former COMECOM, and bilateral comparisons, has been held since 1962 [60].

South Africa's national radioactivity measurement standard is maintained by the National Metrology Laboratory (NML) of the Council for Scientific and Industrial Research (CSIR). Standardizations are undertaken by a number of direct methods utilizing liquid scintillation counting (LSC) [80].

Comparisons of activity measurements for I-131, Tl-201 and Tc-99m with radionuclide calibrators were organized in Cuba since 2002. During 2002, the Radionuclide Metrology Department of the Isotope Center (CENTIS-DMR) has organized several comparisons with various radionuclides in order to obtain information on the quality of the activity measurements during production and administration of radiopharmaceuticals in Cuba [81].

The Australian Radiation Protection and Nuclear Safety Agency (ARPANSA) conducts a series of Radiopharmaceutical Quality Assurance Test Program under a Memorandum of Understanding (MOU) between ARPANSA and the Therapeutic Goods Administration (TGA). For example, in 2005, 46 batches of 24 different types of radiopharmaceuticals, e.g., ready to use radiopharmaceuticals and kits for the preparation of Tc-99m were tested. Two percent in 46 batches of radiopharmaceuticals tested was failure to meet full specifications [82].

International comparison program of national metrological institutes for the standardization of Fe-55, which is a suitable radionuclide standard for X-ray spectrometers, was held by the Comité Consultative pour les Etalons de Mesures des Rayonnements Ionisants (CCEMRI) of the Bureau International des Poids et Mesures (BIPM) [62]. National Metrology Institute of Japan - Advanced Industrial Science and Technology (NMIJ/AIST, Japan) and National Institute of Ionizing Radiation Metrology (ENEA-INMRI, Italy) have been involved in recent years, particularly those relevant in the frame of the international cooperation coordinated by the BIPM and the International Committee for Radionuclide Metrology (ICRM). Particular research activities are devoted on the field of the nuclear safety, nuclear medicine and environmental radionuclide measurements. [83]. International comparisons held by BIPM also can be traced by laboratories such as National Institute for Physics and Nuclear Engineering (Romania) [59], Laboratorio de Metrologia Nuclear (Brazil) in collaboration with the Laboratório Nacional de Metrologia das Radiações Ionizantes, from Rio de Janeiro [57], Radiation Safety Systems Division, Bhabha Atomic Research Centre (India) [61], and Electrotechnical Laboratory (ETL) (Japan) [69].

The Ce-139 measurements formed part of a regional comparison organized by the Asia Pacific Metrology Programme (APMP) [68]. 
The National Institute of Standards and Technology (NIST) maintains a program for the establishment and dissemination of activity measurement standards in nuclear medicine, i.e. Ga-67, Y-90, Tc-99m, Mo-99, In-111, I-125, I-131, and Tl-201 for more than ten years. These standards are disseminated through Standard Reference Materials (SRMs), Calibration Services, radionuclide calibrator settings, and the NIST Radioactivity Measurement Assurance Program (NRMAP, formerly the NEI/NIST MAP). For over 3600 comparisons, $96 \%$ of the participants' results differed from that of NIST by less than $10 \%$, with $98 \%$ being less than $20 \%$. The percentage of participants results within $10 \%$ of NIST ranges from $88 \%$ to $98 \%$ [79].

Measurements from a variety of types of detectors including, ionization chambers, radionuclide calibrators, solid state detectors, Ge detectors, NaI(Tl) detectors, liquid scintillation counters (LSC), Cherenkov counting, and proportional counter are reported [79].

\subsection{Nuclear medicine imaging}

\subsubsection{PET, CT, PET/CT, and SPECT imaging}

PET, CT, PET/CT, and SPECT are non-invasive imaging tools and applied for creating two dimensional (2D) cross section images of three dimensional (3D) objects. PET and SPECT can potentially provide functional or biochemical information by measuring distribution and kinetics of radiolabelled molecules, whereas CT visualizes X-ray density in tissues in the body. The PET imaging in oncology has been migrating from the use of dedicated PET scanners to the use of PET/CT tomographs. This is due to the advantages that PET/CT offers over dedicated PET. One of these advantages is that the integration of PET and CT imaging into a single scanning session allows excellent fusion of the acquired data. Although these nuclear medicine imaging tools provide many advantages and applications in diagnosing diseases clinically, they also poses some challenges and induce artifacts and quantitative errors that can affect the image quality.

\subsubsection{Risks of artifact in PET, CT, and SPECT imaging}

Artifacts and pitfalls can arise at any stage in the process of nuclear medicine imaging and can be grouped into issues related to the (i) patient, (ii) the equipment, or the technologist.

(a) Patient-related risks:

In PET/CT, the patient-related artifacts commonly found are due to metallic implants, truncation, and respiratory motion (or patient motion). These artifacts occur because the CT scan is used to replace a PET transmission scan for the purpose of attenuation correction of the PET data.

Metallic implants, such as dental fillings, hip prosthetics, or chemotherapy ports, cause high CT numbers and generate streaking artifacts on CT images due to their high photon absorption $[85,86]$. This increase CT numbers causes correspondingly high PET attenuation coefficients, resulting in an overestimation of the PET activity and thereby to a falsepositive PET finding. 
In PET/CT, truncation artifacts occur due to the difference in size of the field of view between the CT $(50 \mathrm{~cm})$ and PET $(70 \mathrm{~cm})$ tomographs $[87,88]$ and frequently seen in large patients or patients scanned with arms down, such as in the case of melanoma and head and neck indications. When a patient extends beyond the CT field of view, the extended part of the anatomy is truncated and consequently is not represented in the reconstructed CT image. Truncation also causes streaking artifacts at the edge of the CT image, leading to an overestimation of the attenuation coefficients used to correct the PET data. This increase in attenuation coefficients creates a rim of high activity at the truncation edge, resulting in the misinterpretation of the PET scan.

The most prevalent artifact in PET/CT imaging is respiratory motion during scanning. The artifact is due to the discrepancy between the chest position on the CT image and the chest position on the PET image. PET images are acquired over time periods (time frames) that can vary from a few seconds to tens of minutes. Therefore, during such time periods various motions may have significant effects on the PET images. Both respiratory and contraction induced heart motions have major effect (source of error) on PET imaging of cardiac and thoracic regions. Some equipment, e.g., dose calibrators for the measurements of quantitative measurements is calibrated against or traceable to a reference source of whole body tomographs [89]. Because of the long acquisition time of a PET scan, it is acquired while the patient is freely breathing. The final image is hence an average of many breathing cycles. On the other hand, a CT scan is usually acquired during a specific stage of the breathing cycle. This difference in respiratory motion between PET scans and CT scans results in breathing artifacts on PET/CT images. Several literatures have described this problem [90-91]. The artifacts resulted from respiratory motion or patient motion is also commonly found in myocardial perfusion SPECT. This is because that SPECT requires that the object of interest remains constant for the duration of the acquisition [92-93]. Visually detectable patient motion has been reported in $36 \%$ of clinical studies in one study [94] and $43 \%$ in another [95].

Source of clinical problems of the patients were also indicated by Hladik III, including (i) special patient populations, e.g., pregnant or breast-feeding women, pediatric and geriatric patients, patients requiring dialysis, incontinent, catheterized or miscellaneous patients, (ii) insufficient patient care, education, and preparation, e.g. insufficient patient instruction, shielding or protection in exposure and contamination problems, pregnancy testing, withholding xanthine-containing foods and drug-drug interaction prior to imaging, delay in the administration or imaging, metal implants of patient, (iii) improper behavior of patient, e.g., excessive movement, contamination from incontinence, attenuation from jewelry, prostheses, or implants, etc., and (iv) unexpected altered biodistributions may be undetectable, adverse reactions or untoward effects, [96]

(b) Equipment- or technologist-related risks:

There are several patient-related artifacts and interpretation pitfalls that can potentially compromise nuclear medicine imaging, as discussed above. In order to minimize or identify these artifacts, technologists play an important role in recognizing and correcting them. For example, technologists should ask patients to remove all metallic objects before imaging and should document the location of non-removable metallic objects to minimize or identify the 
artifacts from metallic implants. In PET/CT imaging, it is crucial for technologists to carefully position patients at the center of the field of view and with arms above head to reduce truncation artifacts. Moreover, in order to minimize the artifacts from respiratory motion and produce accurately quantifiable images, it is also essential that technologists instruct patients about breath-hold techniques before the scanning session.

Moreover, sources of clinical problems of error medication also include fail of (i) patient identification, (ii) dosage prescription and administration, (iii) radionuclide administration, (iv) radiopharmaceutical prescription and administration in kinetics or finished product purity testing, (v) interventional medications, (vi) injection technique, (vii) radiopharmaceutical labelled, (viii) preparation or execution of diagnostic or therapeutic procedure, and (ix) radiation protection $[7,96]$.

QC performed on nuclear medicine cameras provides the confidence to technologists and physicians that a scan supplies an accurate representation of the radioisotope distribution in the patient. The instrumentation for nuclear medicine imaging is more complex than that used for whole-body and planar imaging, and requires careful quality control to ensure optimum performance. According to the standards, the main performance parameters are divided into two groups. The first group includes basic intrinsic measurements: spatial resolution in axial and transaxial directions, sensitivity, count rate capabilities by measuring the system dead time and the generation of random events at different radioactivity levels, and scatter fraction of $\gamma$ rays emitted by the annihilation of positron. The second group includes measurements of the accuracy of corrections for physical effects, specifically: uniformity correction, scatter correction, attenuation correction, and count rate linearity correction. Other possible tests to be added to the list of acceptance or performance tests such as: noise equivalent count rate, partial volume and spillover, motion artefacts, image quality test, and PET/CT image co-registration [89].

Nuclear medicine imaging increases the accuracy of diagnosis by combining anatomic information with functional imaging. It is highly dependent on a host of technical considerations. Knowledgeable technologists can minimize or reduce artifacts and other potential problems with image acquisition and, in that way, produce better-quality images.

\section{Conclusion}

Implement of ICH QbD for the radiopharmaceutical manufacturing and imaging technology can be harmonized to a globalized framework in accordance with the regulations and requirements of U.S. FDA, IAEA, WHO and EANM. The attributes of the components in the quality unit (QA/QC), including the aspects of organization, staffing and personnel, facilities, instrumentation and equipment, operation procedure, radiopharmaceuticals, protocol and conduct of a study or a treatment, records and reports, and audit were reviewed and indentified. Critical quality attributes (CQAs) for assuring accurate radioactive dosimetry calculation in the efficiency tracing of absolute activity measurement and in the patient- and technologist-related risks for nuclear medicine imaging (PET, CT, and SPECT), i.e. potential 
sources of error or uncertainty, were elucidated. Although there still have many hard-tocontrolled quantitative errors and artifacts that can eventually affect the quality of imaging, therapeutic efficacy, or safety, it is important for the facility staffs to be aware and continual improvement of these quality factors. By reducing uncertainty and risk or increasing process knowledge and product understanding resulting from $\mathrm{QbD}$ can significantly improve the efficiency of manufacturing processes.

\section{Abbreviations}

API Active pharmaceutical ingredient

ARPANSA Australian Radiation Protection and Nuclear Safety Agency

BNMS British Nuclear Medicine Society

BIPM Bureau International des Poids et Mesures (France)

CT Computed Tomography

CFR Code of Federal Regulations (U.S.)

CMC Chemistry, and manufacturing and controls

CQAs Critical quality attributes

CSIR Council for Scientific and Industrial Research

CGMP Current Good Manufacturing Practice

CGRPP Current Good Radiopharmacy Practice (EU)

EC Ethical Committee (EU)

EANM European Association of Nuclear Medicine (EU)

EDQM European Directorate for the Quality of Medicines \& HealthCare

EIND Exploratory IND (FDA, U.S.)

FDA U.S. Food and Drug Administration

HPLC High-performance liquid chromatography

ICH International Conference on Harmonisation

IMP Investigational Medicinal Product (for drugs used in clinical trials of EU)

IND Investigational new drug

IAEA International Atomic Energy Agency

IRDS Investigational Radiopharmaceutical Drug Service

LSC Liquid scintillation counting 
MA Marketing authorization (EU)

MS Mass spectrometry

MOU Memorandum of Understanding

NRC Nuclear Regulatory Commission

NCA National Competent Authority (EU)

PET Positron emission tomography

QA Quality assurance

QC Quality control

QP Qualified persons who are professional responsible for the release of a drug in Europe

QbD Qulaity by design

RPR Responsible person for the small-scale preparation of radiopharmaceuticals

RDRC Radioactive Drug Research Committee (FDA, U.S.)

SPECT Single photon emission computed tomography

SSRP Small-scale "in-house" radiopharmaceutical

SOP Standard operating procedure

TGA Therapeutic Goods Administration

TLC Thin layer chromatography

USP United States Pharmacopeia

WHO World Health Organization

\section{Author details}

Kung-Tien Liu ${ }^{1 *}$, Jian-Hua Zhao ${ }^{2}$, Lee-Chung Men² and Chien-Hsin Chen ${ }^{1}$

*Address all correspondence to: ktliu@ecic.com.tw

1 Everlight Chemical Industrial Corporation,, Taiwan

2 Chemistry Division, Institute of Nuclear Energy Research,, Taiwan

\section{References}

[1] International Conference on Harmonisation. (2009). ICH Harmonised Tripartite Guideline, Pharmaceutical Development, Q8 (R2)., http://www.ich.org/fileadmin/ 
Public_Web_Site/ICH_Products/Guidelines/Quality/Q8_R1/Step4/Q8_R2_Guideline.pdf.

[2] International Conference on Harmonisation. (2005). ICH Harmonised Tripartite Guideline, Quality Risk Management, Q9., http://www.ich.org/fileadmin/Public_Web_Site/ ICH_Products/Guidelines/Quality/Q9/Step4/Q9_Guideline.pdf.

[3] International Conference on Harmonisation. (2008). ICH Harmonised Tripartite Guideline, Pharmaceutical Quality System, Q10., http://www.ich.org/fileadmin/ Public_Web_Site/ICH_Products/Guidelines/Quality/Q10/Step4/Q10_Guideline.pdf.

[4] International Atomic Energy Association. (2010). Planning a Clinical PET Centre. http://www-pub.iaea.org/MTCD/publications/PDF/Pub1457_web.pdf.

[5] Zimmerman, B. E., Herbst, C., Norenberg, J. P., \& Woods, M. J. (2006). International Guidance on the Establishment of Quality Assurance Programmes for Radioactivity Measurement in Nuclear Medicine. Applied radiation and isotopes, 64(10), 1142-1146.

[6] International Atomic Energy Association. (2009). Quality Assurance for SPECT systems. http://www-pub.iaea.org/MTCD/publications/PDF/Pub1394_web.pdf.

[7] Bergmann, H., Busemann-Sokole, E., \& Horton, P. W. (1995). Quality Assurance and Harmonisation of Nuclear Medicine Investigations in Europe. European Journal of $\mathrm{Nu}$ clear Medicine and Molecular Imaging, 22(5), 477-480.

[8] Chuck, A., Jacobs, P., Logus, J. W., St, Hilaire. D., Chmielowiec, C., \& Mc Ewan, A. J. B. (2005). Marginal Cost of Operating a Positron Emission Tomography Center in a Regulatory Environment International. Journal of Technology Assessment in Health Care, 21(4), 442-451.

[9] Norenberg, J. P., Petry, N. A., \& Schwarz, S. (2010). Operation of a Radiopharmacy for a Clinical Trial. Seminars in Nuclear Medicine, 40, 347-356.

[10] Decristoforo, C., \& Schwarz, S. W. (2011). Radiopharmacy: Regulations and Legislations in Relation to Human Applications. Drug Discovery Today: Technologies, 8(2-4), e71-77.

[11] European Association of Nuclear Medicine. (2007). Guidelines on current good Radiopharmacy Practice (cGRPP) in the Preparation of Radiopharmaceuticals, Version 2., http:// www.eanm.org/publications/guidelines/gl_radioph_cgrpp.pdf.

[12] Elsinga, P., Todde, S., Penuelas, I., Meyer, G., Farstad, B., Faivre-Chauvet, A., et al. (2010). Guidance on Current Good Radiopharmacy Practice (CGRPP) for the SmallScale Preparation of Radiopharmaceuticals. European Journal of Nuclear Medicine and Molecular Imaging., 37(5), 1049-1062.

[13] World Health Organization. (2003). WHO Expert Committee on Specifications for Pharmaceutical Preparations- WHO Technical Report Series, 908-Thirtyseventh Report., http:// whqlibdoc.who.int/trs/who_trs_908.pdf. 
[14] Barbet, J., Kraeber-Bodéré, F., \& Chatal, J. F. (2008). Review: What Can Be Expected from Nuclear Medicine Tomorrow? Cancer biotherapy and radiopharmaceuticals, 23(4), 483-504.

[15] International Atomic Energy Agency. (2001, 18-22 January 1999). Paper presented at Therapeutic Applications of Radiopharmaceuticals, Proceedings of an International Seminar, Held in Hyderabad, India. http://www-pub.iaea.org/MTCD/ publications/PDF/te_1228_prn.pdf.

[16] Atkinson, B. J., \& Tu, S. M. (2011). Radiopharmaceuticals: Present and Future. Journal of Supportive Oncology, 9(6), 206-207.

[17] Zimmerman, B. E., Cessna, J. T., \& Schima, F. J. (1998). The Standardization of the Potential Bone Palliation Radiopharmaceutical 117mSn (+4) Dtpa. Applied radiation and isotopes., 49(4), 317-328.

[18] Kung, H. F., Kung, M. P., \& Choi, S. R. (2003). Radiopharmaceuticals for Single-Photon Emission Computed Tomography Brain Imaging. Seminars in Nuclear Medicine, 33(1), 2-13.

[19] Imam, S. K. (2005). Molecular Nuclear Imaging: The Radiopharmaceuticals (Review). Cancer biotherapy and radiopharmaceuticals, 20(2), 163-172.

[20] Wong, F. C., \& Kim, E. E. (2009). A Review of Molecular Imaging Studies Reaching the Clinical Stage. European Journal of Radiology, 70(2), 205-211.

[21] Glaser, M., Luthra, S. K., \& Brady, F. (2003). Applications of Positron-Emitting Halogens in Pet Oncology (Review). International Journal of Oncology, 22(2), 253-268.

[22] Elsinga, P. H. (2002). Radiopharmaceutical Chemistry for Positron Emission Tomography. Methods, 27(3), 208-217.

[23] Srivastava, S., \& Dadachova, E. (2001). Recent Advances in Radionuclide Therapy. Seminars in Nuclear Medicine, 31, 330-341.

[24] Jastrzebski, J. (2012). Radioactive Nuclei for Medical Applications. Acta Physica Polonica $B, 43(3), 49-70$.

[25] Miederer, M., Scheinberg, D. A., \& Mc Devitt, M. R. (2008). Realizing the Potential of the Actinium-225 Radionuclide Generator in Targeted Alpha Particle Therapy Applications. Advanced drug delivery reviews, 60(12), 1371-1382.

[26] International Atomic Energy Agency. (2009). Therapeutic Radionuclide Generators: Sr-90/Y-90 and W-188/Re-188 Generators.., http://www-pub.iaea.org/MTCD/publications/PDF/trs470_web.pdf.

[27] Al-Nahhas, A., Win, Z., Szyszko, T., Singh, A., Nanni, C., Fanti, S., et al. (2007). Gallium-68 PET: A New Frontier in Receptor Cancer Imaging. Anticancer research, 27(6B), 4087-4094. 
[28] Anderson, C. J., \& Ferdani, R. (2009). Copper-64 Radiopharmaceuticals for PET Imaging of Cancer: Advances in Preclinical and Clinical Research. Cancer Biotherapy and Radiopharmaceuticals., 24(4), 379-393.

[29] Farncombe, T. H., Gifford, H. C., Narayanan, M. V., Pretorius, P. H., Frey, E. C., \& King, M. A. (2004). Assessment of Scatter Compensation Strategies for 67Ga SPECT Using Numerical Observers and Human Lroc Studies. Journal of Nuclear Medicine, 45(5), 802-812.

[30] Rajendran, J. G., Eary, J. F., Bensinger, W., Durack, L. D., Vernon, C., \& Fritzberg, A. (2002). High-Dose 166Ho-Dotmp in Myeloablative Treatment of Multiple Myeloma: Pharmacokinetics, Biodistribution, and Absorbed Dose Estimation. Journal of Nuclear Medicine., 43(10), 1383-1390.

[31] Schmitt, A., Bernhardt, P., Nilsson, O., Ahlman, H., Kölby, L., Maecke, H. R., et al. (2004). Radiation Therapy of Small Cell Lung Cancer with 177Lu-Dota-Tyr3-Octreotate in an Animal Model. Journal of Nuclear Medicine.; , 45(9), 1542-1548.

[32] Rahmim, A., \& Zaidi, H. (2008). Pet Versus Spect: Strengths, Limitations and Challenges. Nuclear Medicine Communications, 193-207.

[33] Bateman, T. M. (2012). Advantages and Disadvantages of PET and SPECT in a Busy Clinical Practice. Journal of Nuclear Cardiology, 19, S3-S11.

[34] De Decker, M., \& Dierckx, R. A. (2005). The Good Laboratory Practice and Good Clinical Practice Requirements for the Production of Radiopharmaceuticals in Clinical Research. Nuclear Medicine Communications, 575-579.

[35] Patidar, A. K., Patidar, P., Tandel, T. S., Mobiya, A. K., Selvam, G., \& Jeyakandan, M. (2010). Current Trends in Nuclear Pharmacy Practice. International Journal of Pharmaceutical Sciences Review and Research, 5(2), 145-150.

[36] Laven, D. L., \& Martin, W. R. (1989). Justification for Hospital-Based Nuclear Pharmacy Services. Journal of Pharmacy Practice, 2(3), 152-161.

[37] Mac, Farlane. C. R. (2006). Acr Accreditation of Nuclear Medicine and PET Imaging Departments. Journal of Nuclear Medicine Technology, 34(1), 18-24.

[38] Jarritt, P. H., Perkins, A. C., \& Woods, S. D. (2004). Audit of Nuclear Medicine Scientific and Technical Standards. Nuclear Medicine Communications, 77-75.

[39] Organisation for Economic Co-operation and Development. (1998). OECD Series on Principles of Good Laboratory Practice and Compliance Monitoring. , OECD Principles on Good Laboratory Practice, 1

[40] Callahan, R. J., Chilton, H. M., Ponto, J. A., Swanson, D. P., Royal, H. D., \& Bruce, A. D. (2007). Procedure Guideline for the Use of Radiopharmaceuticals 4.0. Journal of Nuclear Medicine Technology, 35(4), 272-275. 
[41] Bombardieri, E., Aktolun, C., Baum, R. P., Bishof-Delaloye, A., Buscombe, J., Chatal, J. F., et al. (2003). Bone Scintigraphy: Procedure Guidelines for Tumour Imaging. European Journal of Nuclear Medicine and Molecular Imaging, 30(12), 99-106.

[42] Donohoe, K. J., Brown, M. L., \& Collier, B. D. ((2003). ). Society of Nuclear Medicine Procedure Guideline for Bone Scintigraphy. Bone Scintigraphy , 205-209.

[43] Delbeke, D., Coleman, R. E., Guiberteau, M. J., Brown, M. L., Royal, H. D., Siegel, B. A., et al. (2006). Procedure Guideline for SPECT/CT Imaging 1.0. Journal of Nuclear Medicine, 47(7), 1227-1234.

[44] Strauss, H. W., Miller, D. D., Wittry, M. D., Cerqueira, M. D., Garcia, E. V., Iskandrian, A. S., et al. (2008). Procedure Guideline for Myocardial Perfusion Imaging 3.3. Journal of Nuclear Medicine Technology, 36(3), 155-161.

[45] Stelmach, H., \& Quinn, J. L. (1974). Radiopharmaceutical Quality Control. Seminars in Nuclear Medicine, 4, 295-303.

[46] Ahuja, S., \& Scypinski, S. (2001). Handbook of Modern Pharmaceutical Analysis. Academic Press.

[47] Harapanhalli, R. S. (2010). Food and Drug Administration Requirements for Testing and Approval of New Radiopharmaceuticals. Seminars in Nuclear Medicine, 40, 364-384.

[48] Hoffman, J. M., Gambhir, S. S., \& Kelloff, G. J. (2007). Regulatory and Reimbursement Challenges for Molecular Imaging1. Radiology., 245(3), 645-660.

[49] Belcher, E. H. (1953). Scintillation Counters Using Liquid Luminescent Media for Absolute Standardization and Radioactive Assay. Journal of Scientific Instruments, 30, 286 -289 .

[50] Troughton, M. E. C. (1966). The Absolute Standardization of Cobalt-57. The International Journal of Applied Radiation and Isotopes, 17(3), 145-150.

[51] Günther, E. (2002). What Can We Expect from the Ciemat/Nist Method? Applied Radiation and Isotopes, 56(1-2), 357-360.

[52] Schönfeld, E., Schötzig, U., Günther, E., \& Schrader, H. (1994). Standardization and Decay Data of 68ge/68ga. Applied Radiation and Isotopes, 45(9), 955-961.

[53] Plch, J., Zderadicka, J., \& Kokta, L. (1974). Coincidence Methods of Standardization for $131 \mathrm{cs}$ and Measurement of Decay Parameters. The International Journal of Applied Radiation and Isotopes., 25(10), 433-444.

[54] Barquero, L., \& Roteta, M. (2002). Standardization of $134 \mathrm{cs}$ by Three Methods. Applied Radiation and Isotopes., 56(1-2), 211-214.

[55] Funck, E., Debertin, K., \& Walz, K. F. (1983). Standardization and Decay Data of 201tl. International Journal of Nuclear Medicine and Biology, 137-140. 
[56] Hult, M., Altzitzoglou, T., Denecke, B., Persson, L., Sibbens, G., \& Reher, D. F. G. (2000). Standardisation of 204tl at Irmm. Applied Radiation and Isotopes, 52(3), 493-498.

[57] Dias, M. S., \& Koskinas, M. F. (2003). Standardization of a 204tl Radioactive Solution. Applied Radiation and Isotopes, 58(2), 235-238.

[58] Woods, D. H., Bowles, N. E., Jerome, S. M., de Lavison, P., Lineham, S., Makepeace, J. L., et al. (2000). Standardisation of 210pb. Applied Radiation and Isotopes, 52(3), 381-385.

[59] Sahagia, M., Razdolescu, A., Grigorescu, E. L., Luca, A., \& Ivan, C. (2000). The Standardization of a 204tl Solution. Applied Radiation and Isotopes, 52(3), 487-491.

[60] Sahagia, M., Razdolescu, A. C., Grigorescu, E. L., Luca, A., \& Ivan, C. (2006). Results Obtained by the Radionuclide Metrology Laboratory of IFIN-HH, in the International Comparisons of Standard Solutions, During 2002-2004. Romanian Journal of Physics, $51,21-26$.

[61] Kulkarni, D. B., Reddy, P. J., Bhade, S. P. D., Narayan, K. K., Narayanan, A., Krishnamachari, G., et al. (2006). Comparison of Efficiency Tracing and Zero Detection Threshold Techniques with Ciemat/Nist Standardization Method under Different Quench Conditions with Liquid Scintillation Spectrometer. Current science, 90(1), 83-87.

[62] Koskinas, M. F., Pires, C. A., Yamazaki, I. M., et al. (2008). Standardization of 55Fe by Tracing Method. Kidlington, Royaume-Uni: Elsevier.

[63] Sochorová, J., Auerbach, P., \& Havelka, M. (2008). Application Of "Wet" Extrapolation Method for Activity Standardisation of Electron Capture Radionuclides. Applied Radiation and Isotopes., 66(6), 919-924.

[64] Gunther, E. W. (1994). Standardization of 59Fe and 131I by Liquid Scintillation Counting. Nuclear Instruments and Methods in Physics Research Section A: Accelerators, Spectrometers, Detectors and Associated Equipment, 339(1-2), 402-407.

[65] Simpson, B. R. S., \& Meyer, B. R. (1998). Activity Measurement of 55Fe by an Efficiency Calculation Method. Applied Radiation and Isotopes, 1073-1076.

[66] Simpson, B. R. S., \& Morris, W. M. (2004). Direct Activity Determination of 54Mn and $65 Z$ n by a Non-Extrapolation Liquid Scintillation Method. Applied Radiation and Isotopes, 60(2), 475-479.

[67] Dias, M. S., Silva, F. F. V., \& Koskinas, M. F. (2010). Standardization and Measurement of Gamma-Ray Probability Per Decay of 177Lu. Applied Radiation and Isotopes, $1349-1353$.

[68] Van Wyngaardt, W. M., \& Simpson, B. R. (2006). Absolute Activity Measurement of the Electron-Capture-Based Radionuclides 139Ce, 125I, 192Ir and 65Zn by Liquid Scintillation Coincidence Counting. Applied radiation and isotopes: including data, in- 
strumentation and methods for use in agriculture, industry and medicine, 64(10-11), 1454 -1458 .

[69] Hino, Y., Matui, S., Yamada, T., Takeuchi, N., Onoma, K., Iwamoto, S., et al. (2000). Absolute Measurement of 166mHo Radioactivity and Development of Sealed Sources for Standardization of $\gamma$-Ray Emitting Nuclides. Applied Radiation and Isotopes, 52(3), 545-549.

[70] Broda, R., Péron, M. N., Cassette, P., Terlikowska, T., \& Hainos, D. (1998). Standardization of 139Ce by the Liquid Scintillation Counting Using the Triple to Double Coincidence Ratio Method. Applied Radiation and Isotopes, 1035-1040.

[71] Cassette, P., Broda, R., Hainos, D., \& Terlikowska, T. (2000). Analysis of DetectionEfficiency Variation Techniques for the Implementation of the TDCR Method in Liquid Scintillation Counting. Applied Radiation and Isotopes, 52(3), 643-648.

[72] Johansson, L. C., \& Sephton, J. P. (2010). Validation of a New TDCR System at NPL. Applied radiation and isotopes, $1537-1539$.

[73] Kossert, K. (2010). Activity Standardization by Means of a New Tdcr-Cerenkov Counting Technique. Applied radiation and isotopes, 68(6), 1116-1120.

[74] Coursey, B. M., Cessna, J., Garcia-Torano, E., Golas, D. B., Grau, Malonda. A., Gray, D. H., et al. (1991). The Standardization and Decay Scheme of Rhenium-186. International Journal of Radiation Applications and Instrumentation Part A Applied Radiation and Isotopes., 42(9), 865-869.

[75] Schönfeld, E., Janssen, H., Schotzig, U., Gunther, E., \& Schrader, H. (1994). Standardization and Decay Data of 186Re. Nuclear Instruments and Methods in Physics Research Section A: Accelerators, Spectrometers, Detectors and Associated Equipment, 339(1-2), 174-179.

[76] Günther, E. (2000). Standardization of 237np by the Ciemat/Nist Lsc Tracer Method. Applied Radiation and Isotopes., 52(3), 471-474.

[77] Koskinas, M. F., Fonseca, K. A., \& Dias, M. S. (2002). Disintegration Rate Measurement of a 152Eu Solution. Applied Radiation and Isotopes, 56, 1-2, 441-445.

[78] Švec, A. (2009). Interpretation of Ionization Chamber Efficiency Curves. Metrologia, 43-46.

[79] Cessna, J. T., \& Golas, D. B. (2012). The Nist Radioactivity Measurement Assurance Program for the Radiopharmaceutical Industry. Applied radiation and isotopes.

[80] Simpson, B.R.S. (2002). Radioactivity Standardization in South Africa. Applied Radiation and Isotopes, 56(1-2), 301-305.

[81] Oropesa, P., Hernández, A. T., Serra, R., Martinez, E., \& Varela, C. (2003). Comparisons of Activity Measurements with Radionuclide Calibrators. Applied Radiation and Isotopes, 59(5-6), 383-387. 
[82] Ivanov, Z. (2006). Results of the Quality Assurance Testing Program for Radiopharmaceuticals (2005), Version 3. Australian: Australian Radiation Protection and Nuclear Safety Agency, http://www.arpansa.gov.au/pubs/technicalreports/tr144.pdf.

[83] Capogni, M., De Felice, Y., Saito, N., \& De Felice, P. (2011). Ionising Radiation Metrology in the Field of Nuclear and Life Science Applications, http://www.enea.it/it/internazionali/eventi-internazionali/enea-in-japan-2011/radiation-metrology/capogni.pdf.

[84] Hino, Y., \& Ohgaki, H. (1998). Absolute Measurement of 192Ir. Applied Radiation and Isotopes, 1179-1183.

[85] Goerres, G. W., Hany, T. F., Kamel, E., von Schulthess, G. K., \& Buck, A. (2002). Head and Neck Imaging with PET and PET/CT: Artefacts from Dental Metallic Implants. European journal of nuclear medicine, 29(3), 367-370.

[86] Kamel, E. M., Burger, C., Buck, A., von Schulthess., G. K., \& Goerres, G. W. (2003). Impact of Metallic Dental Implants on CT-Based Attenuation Correction in a Combined PET/CT Scanner. European radiology, 13(4), 724-728.

[87] Carney, J., Townsend, D. W., Kinahan, P. E., Beyer, T., Kachelriess, M., Kalender, W. A., et al. (2001). CT-Based Attenuation Correction: The Effects of Imaging with the Arms in the Field of View. Journal of Nuclear Medicine (suppl) , 42, 56P-57P.

[88] Mawlawi, O., Pan, T., \& Cody, D. D. (2004). Evaluation of a New CT Truncation Correction Algorithm for Accurate Quantification of PET/CT Images. Journal of Nuclear Medicine (suppl): , 45, 413P.

[89] Teräs, M. (2008). Performance and Methodological Aspects in Positron Emission Tomography. Finland, University of Turku.

[90] Osman, M. M., Cohade, C., Nakamoto, Y., \& Wahl, R. L. (2003). Respiratory Motion Artifacts on PET Emission Images Obtained Using CT Attenuation Correction on PET-CT. European journal of Nuclear Medicine and Molecular Imaging, 30(4), 603-606.

[91] Cohade, C., Osman, M., Marshall, L. T., \& Wahl, R. L. (2003). PET-CT: Accuracy of PET and CT Spatial Registration of Lung Lesions. European Journal of Nuclear Medicine and Molecular Imaging, 30(5), 721-726.

[92] Botvinick, E.H., Zhu, Y.Y., O'Connell, W. J., \& Dae, M. W. (1993). A Quantitative Assessment of Patient Motion and Its Effect on Myocardial Perfusion SPECT Images. Journal of Nuclear Medicine, 34(2), 303-310.

[93] Cooper, J. A., Neumann, P. H., \& Mc Candless, B. K. (1992). Effect of Patient Motion on Tomographic Myocardial Perfusion Imaging. Journal of Nuclear Medicine, 33(8), 1566-1571.

[94] Wheat, J. M., Currie, G. M., \& Ramsay, B. (2006). Visual Quality Control of Gated Myocardial Perfusion SPECT. The Internet Journal of Cardiology, 4(1). 
[95] Wheat, J. M., \& Currie, G. M. (2004). Incidence and Characterization of Patient Motion in Myocardial Perfusion SPECT: Part 1. Journal of Nuclear Medicine Technology, 32(2), 60-65.

[96] Hladik, W. B., \& Norenberg, J. P. (1996). Problems Associated with the Clinical Use of Radiopharmaceuticals: A Proposed Classification System and Troubleshooting Guide. European Journal of Nuclear Medicine and Molecular Imaging, 23(8), 997-1002. 